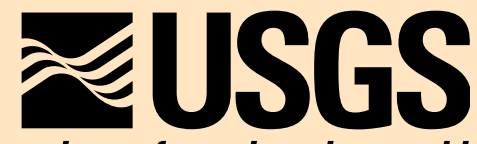

science for a changing world

\title{
Connections Among the Spatial and Temporal Structures in Tidal Currents, Internal Bores, and Surficial Sediment Distributions Over the Shelf off Palos Verdes, California
}

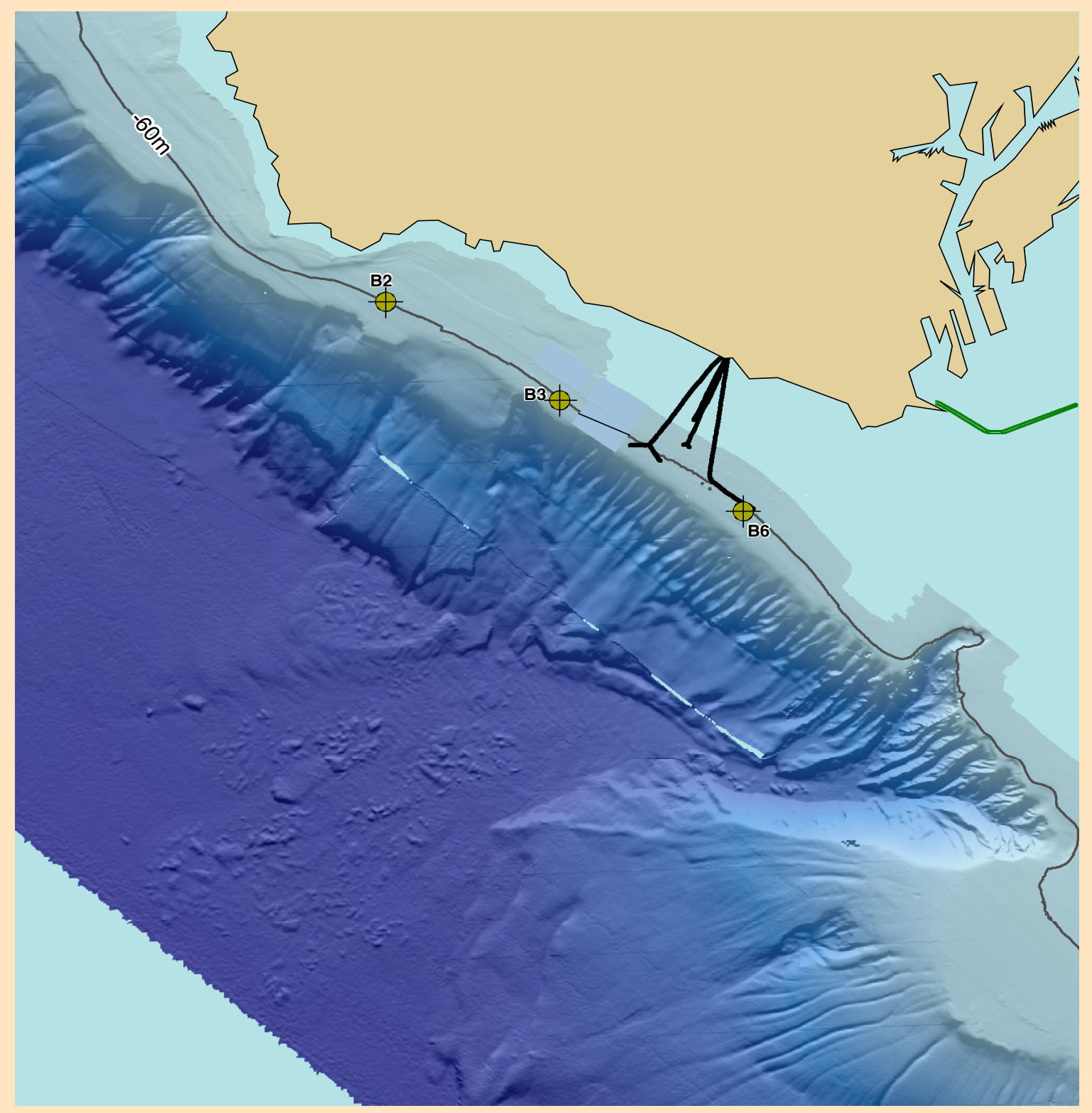

Scientific Investigations Report 2008-5094

U.S. Department of the Interior U.S. Geological Survey 
This page intentionally left blank 


\section{Connections Among the Spatial and Temporal Structures in Tidal Currents, Internal Bores, and Surficial Sediment Distributions Over the Shelf off Palos Verdes, California}

By Marlene A. Noble, Kurt J. Rosenberger, Jingping Xu, Richard P. Signell, and Alex Steele

Scientific Investigations Report 2008-5094 


\title{
U.S. Department of the Interior KEN SALAZAR, Secretary
}

\author{
U.S. Geological Survey \\ Suzette M. Kimball, Acting Director
}

U.S. Geological Survey, Reston, Virginia: 2009 This report and any updates to it are available online at:
http://pubs.usgs.gov/sir/2008/5094/
For additional information write to:
U.S. Geological Survey
Box 25046, Mail Stop 421, Denver Federal Center
Denver, CO 80225-0046
Additional USGS publications can be found at:
http://geology.usgs.gov/index.htm
For more information about the USGS and its products:
Telephone: $1-888-A S K-U S G S$ (1-888-275-8747)
World Wide Web: http://www.usgs.gov/
Any use of trade, product, or firm names in this publication is for descriptive purposes only and does not imply
endorsement by the U.S. Government.
Although this report is in the public domain, it may contain copyrighted materials that are noted in the text. Permission
to reproduce those items must be secured from the individual copyright owners.

\section{Cataloging-in-Publication data are on file with the Library of Congress}

Produced in the Western Region, Menlo Park, California

Manuscript approved for publication, May 27, 2008

Text edited by James W. Hendley II

Layout and design by Stephen L. Scott 


\section{Contents}

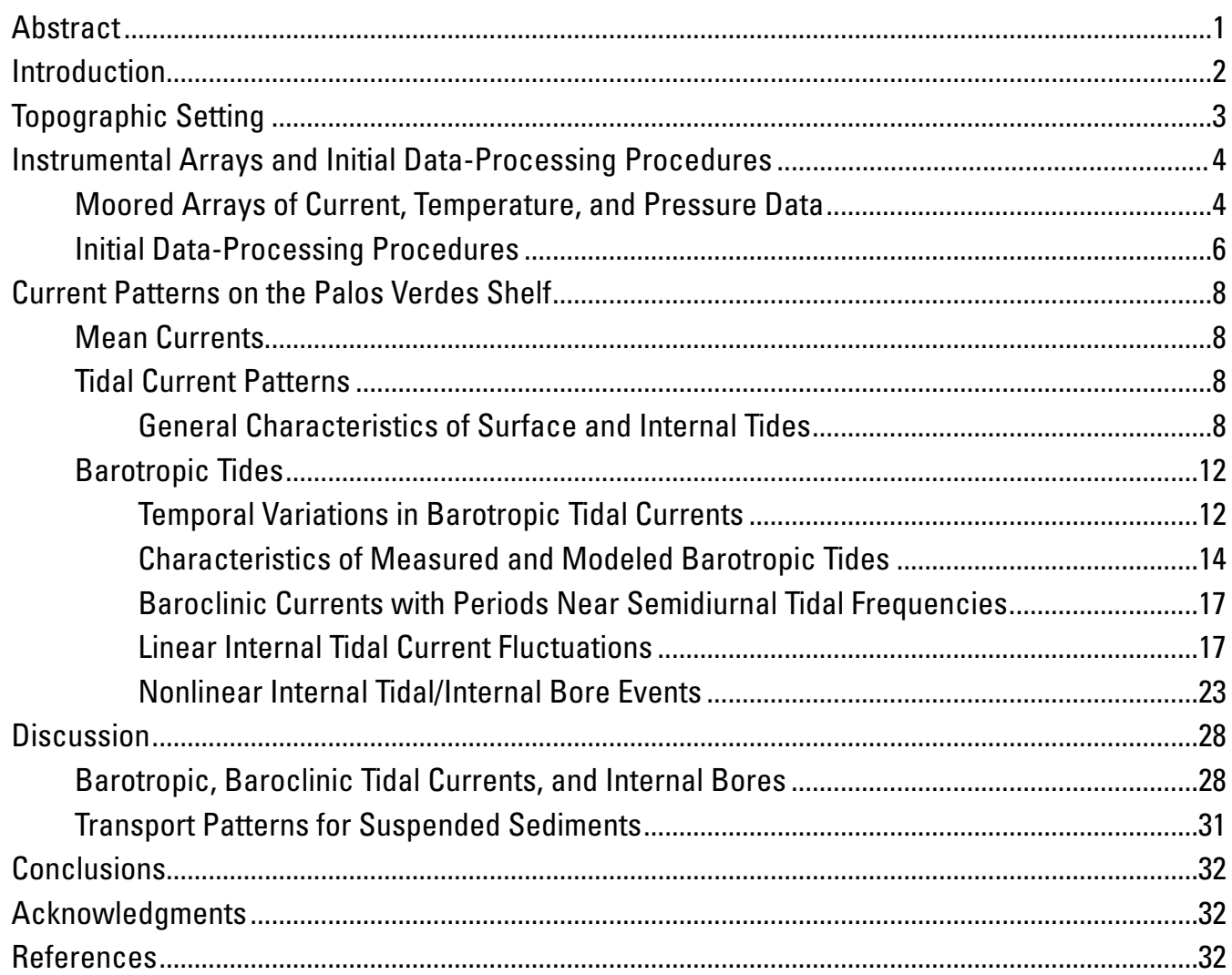

\section{Figures}

1. Location of mooring sites on the Palos Verdes and San Pedro shelves......................................

2. Map of contaminated lens of sediment off the Palos Verdes shelf .............................................

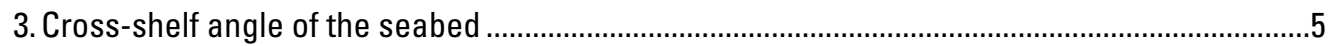

4. Disaggregated mean grain size of surficial sediment on the Palos Verdes shelf ........................6

5. Vertical profiles and evolution of the DDT deposited on the Palos Verdes shelf ........................7

6. Map of slope of the erodability function that indicates the potential erodability

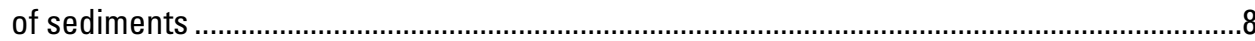

7. Mooring diagram depicting site $A 4$, showing current (ADCP) and temperature

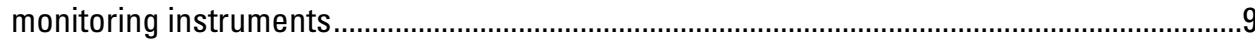

$8 A$. Timelines showing dates when data exists for ADCP instruments..........................................10

$8 B$. Timelines showing dates for bottom pressure measurements on the Palos Verdes shelf .......10

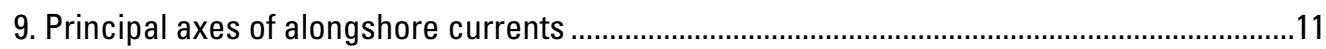

10. Direction of mean current flows at the primary measurement sites........................................12

11. Measured and modeled $\mathrm{M}_{2}$ tidal-current amplitudes and inclination angles...........................18 
12A. Complex demodulation of the internal tidal current record ................................................20

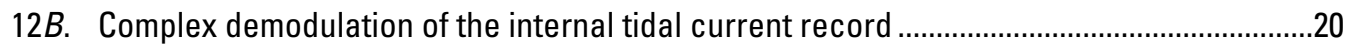

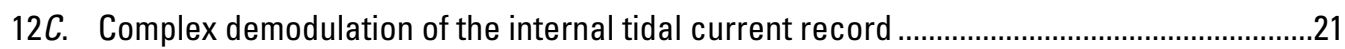

13A. Vertical profile of the amplitude and phase of the $\mathrm{M}_{2}$ internal tidal current ........................22

13B. Vertical profile of the amplitude and phase of the $\mathrm{M}_{2}$ internal tidal current.........................23

13C. Vertical profile of the amplitude and phase of the $M_{2}$ internal tidal current ........................24

13D. Vertical profile of the amplitude and phase of the $\mathrm{M}_{2}$ internal tidal current ........................24

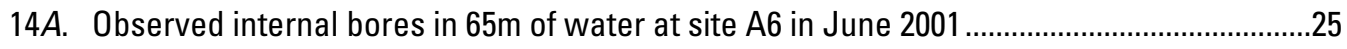

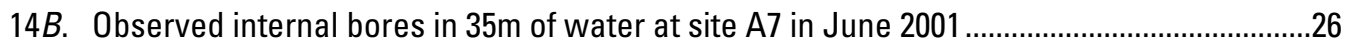

15. Near-bed currents with speeds greater than $20 \mathrm{~cm} / \mathrm{s}$ in the baroclinic records...................27

16A. Category 1 and 2 internal events (see text) at sites $A 6$ and $A 7$...........................................29

16B. Category 1 and 2 internal events (see text) at sites $A 3$ and $A 4$..........................................29

17. Dominant direction of currents at each site in the primary array..........................................30

\section{Tables}

1. Depth in meters of the current bins ...................................................................................11

2. Mean along- and cross-shelf current amplitudes averaged over the entire water column

3. Temporal variability in the amplitude of the principal diurnal and semidiurnal barotropic tidal currents.

4. Amplitude of sea-level fluctuations in the diurnal and semidiurnal and semidiurnal bands

5. Barotropic tidal current characteristics calculated using records that are 739 days

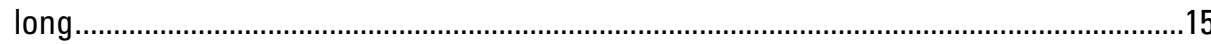

6A. Ratios of barotropic tidal sea-level fluctuations …..........................................................

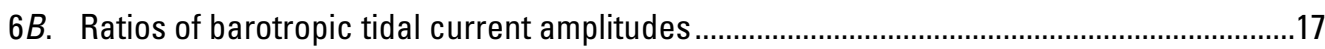

7A. Amplitude of measured and predicted sea-level fluctuations............................................19

7B. Characteristics of measured (Table 5) and modeled barotropic $\mathrm{M}_{2}$ tidal currents over the Palos Verdes and northern San Pedro shelves .................................................19

$8 A$. Characteristics of the $\mathrm{M}_{2}$ internal tides at site $A 3$ calculated using 2-year records ............21

$8 B$. Characteristics of the $M_{2}$ internal tides at site $A 6$ calculated using 2-year records ............21

$8 C$. Characteristics of the $\mathrm{M}_{2}$ internal tides at site $A 4$ calculated using 2-year records ............22

8D. Characteristics of the $\mathrm{M}_{2}$ internal tides at site $A 7$ calculated using 2-year records ............22

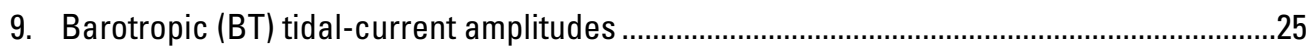

10. Total number of events in the various current records .................................................27

11. The percentages of near-bottom current speeds that are greater than $20 \mathrm{~cm} / \mathrm{s}$.................28 


\title{
Connections Among the Spatial and Temporal Structures in Tidal Currents, Internal Bores, and Surficial Sediment Distributions Over the Shelf off Palos Verdes, California
}

\author{
By Marlene A. Noble ${ }^{1}$, Kurt J. Rosenberger ${ }^{1}$, Jingping $\mathrm{Xu}^{2}{ }^{2}$, Richard P. Signell ${ }^{3}$, and Alex Steele ${ }^{4}$
}

\section{Abstract}

The topography of the Continental Shelf in the central portion of the Southern California Bight has rapid variations over relatively small spatial scales. The width of the shelf off the Palos Verdes peninsula, just northwest of Los Angeles, California, is only 1 to $3 \mathrm{~km}$. About $7 \mathrm{~km}$ southeast of the peninsula, the shelf within San Pedro Bay widens to about $20 \mathrm{~km}$. In 2000, the Los Angeles County Sanitation District began deploying a dense array of moorings in this complex region of the central Southern California Bight to monitor local circulation patterns. Moorings were deployed at 13 sites on the Palos Verdes shelf and within the northwestern portion of San Pedro Bay. At each site, a mooring supported a string of thermistors and an adjacent bottom platform housed an Acoustic Doppler Current Profiler. These instruments collected vertical profiles of current and temperature data continuously for one to two years.

The variable bathymetry in the region causes rapid changes in the amplitudes and spatial structures of barotropic tidal currents, internal tidal currents, and in the associated nonlinear baroclinic currents that occur at approximate tidal frequencies. The largest barotropic tidal constituent is $\mathrm{M}_{2}$, the principal semidiurnal tide. The amplitude of this tidal current changes over fairly short along-shelf length scales. Tidal-current amplitudes are largest in the transition region between the two shelves; they increase from about $5 \mathrm{~cm} / \mathrm{s}$ over the northern San Pedro shelf to nearly $10 \mathrm{~cm} / \mathrm{s}$ on the southern portion of the Palos Verdes Shelf. Tidal-current amplitudes are then reduced to less than $2 \mathrm{~cm} / \mathrm{s}$ over the very narrow section of the northern Palos Verdes shelf that lies just $6 \mathrm{~km}$ upcoast of the southern sites. Models suggest that the amplitude of the barotropic $\mathrm{M}_{2}$ tidal currents, which propagate

\footnotetext{
${ }^{1}$ U.S. Geological Survey, Menlo Park, CA.

${ }^{2}$ U.S. Geological Survey, Santa Cruz, CA.

${ }^{3}$ U.S. Geological Survey, Woods Hole, MA.

${ }^{4}$ County Sanitation District of Los Angeles County, Whittier, CA.
}

toward the northwest primarily as a Kelvin wave, is adjusting to the short topographic length scales in the region. Semidiurnal sea-level oscillations are, as expected, independent of these topographic variations; they have a uniform amplitude and phase structure over the entire region.

Because the cross-shelf angle of the seabed over most of the Palos Verdes shelf is 1 to 3 degrees, which is critical for the local generation and/or enhancement of nonlinear characteristics in semidiurnal internal tides, some internal tidalcurrent events have strong asymmetric current oscillations that are enhanced near the seabed. Near-bottom currents in these events are directed primarily offshore with amplitudes that exceed $30 \mathrm{~cm} / \mathrm{s}$. The spatial patterns in these energetic near-bottom currents have fairly short-length scales. They are largest over the inner shelf and in the transition region between the Palos Verdes and San Pedro shelves. This spatial pattern is similar to that found in the barotropic tidal currents. Because these baroclinic currents have an approximate tidal frequency, an asymmetric vertical structure, and a somewhat stable phase, they can produce a non-zero depthmean flow for periods of a few months. These baroclinic currents can interact with the barotropic tidal current and cause an apparent increase (or decrease) in the estimated barotropic tidal-current amplitude. The apparent amplitude of the barotropic tidal current may change by 30 to 80 percent or more in a current record that is less than three months long.

The currents and surficial sediments in this region are in dynamic equilibrium in that the spatial patterns in bottom stresses generated by near-bed currents from surface tides, internal tides, and internal bores partly control the spatial patterns in the local sediments. Coarser sediments are found in the regions with enhanced bottom stresses (that is, over the inner shelf and in the region between the Palos Verdes and San Pedro shelves). Finer sediments are found over the northwestern portion of the Palos Verdes shelf, where near-bottom currents are relatively weak. The nonlinear asymmetries in the internal tidal-period current oscillations cause a net transport of suspended material along and off the shelf, reinforcing the mean flow patterns that also carry sediment either into Santa Monica Bay or offshore and onto the adjacent slope. 


\section{Introduction}

The central Southern California Bight (SCB), which is dominated by the Los Angeles metropolis, is a heavily urbanized section of the coastal ocean. More than 12 million people live along the coastal corridor between Point Dume at the northern end of Santa Monica Bay and Newport Beach at the southern end of San Pedro Bay (fig. 1). These two fairly small embayments are connected by a very narrow continental shelf off the Palos Verdes peninsula, which is located just west of Los Angeles, California. A large ocean outfall at White's Point, managed by the Los Angeles County Sanitation District (LACSD), discharges treated wastewater onto the southeastern portion of the Palos Verdes shelf. During the 1950s and 1960s, significant amounts of dichlorodiphenyltrichloroethane (DDT) in wastewater from a nearby Montrose chemical plant entered the sewage system. This DDT adhered to fine particles in the wastewater, and these particles were discharged onto the Palos Verdes shelf. Studies have shown that these fine particles accumulated on the central and northwestern portions of the shelf, forming a lens of contaminated sediment primarily upcoast of the outfall (fig. 2) (Lee and others, 2002; Sherwood and others, 2002). The contaminants in the sediments are predominantly DDT and its derivatives, 1-chloro-4-[2,2-dichloro1-(4-chlorophenyl)ethenyl]benzene ( $\mathrm{p}, \mathrm{p}^{\prime}$-DDE) and 1-chloro4-[2-chloro-1-(4-chlorophenyl)ethenyl]benzene (p, $\mathrm{p}^{\prime}$-DDMu). Measurable amounts of polychlorinated biphenyl (PCBs) were also found in the sediments.

In the early 1970s, the release of DDT from the manufacturing plant into the sewage system was terminated, but the residual DDT still within the sewer system continued to be discharged onto the shelf for several years. Eventually, the fine particles in the wastewater discharged onto the shelf were no longer heavily contaminated with DDT. These relatively clean sediments were deposited on top of the contaminated sediments, thereby significantly reducing the erosion and transport of the contaminated sediments by coastal ocean processes. This discharge of the relatively clean suspended sediments was reduced considerably in 1985 when secondary treatment processes essentially eliminated the fine material in the sewage wastewater (LACSD, 1992, 1998; Southern California Coastal Water Research Project (SCCWRP), 1999). Therefore, new material from the outfall could not replace fine material eroded from the cap over the contaminated sediment deposit. It was thought possible that the core of the contaminated deposit, generally buried 10 to $30 \mathrm{~cm}$ beneath the sea floor, could be exposed (Lee and others, 2002; Sherwood and others, 2002).

In 1992, a research program was designed to determine the amount of contaminants in the sediments and to assess the possibility that the contaminants could be eroded and transported to other sites in the coastal ocean (Lee and Wiberg, 2002). The results of this research were not conclusive. Fine material deposited on the shelf was definitely being resuspended and transported out of the region, but was also coming into the region from sites downcoast (southeast) of the outfall. Unfortunately, it could not be determined whether the net transport of material from the downcoast sites was sufficient to replace local losses. It remained possible that the heavily contaminated sediments buried on the Continental Shelf off Palos Verdes would be exposed, resuspended, and transported throughout the central SCB.

In 1996, the U. S. Environmental Protection Agency (EPA) initiated a Superfund investigation of this contaminated region of the Palos Verdes shelf. The goal of the investigation was to determine a proper mitigation strategy to avoid the human health and ecological risks potentially posed by the site. As part of this program, several collaborative research programs involving the EPA, the U.S. Geological Survey (USGS), other federal agencies, associated universities, local municipalities, and consulting companies were undertaken in part to determine (1) the coastal ocean processes responsible for resuspending and transporting sediments in the region, (2) whether spatial and/or temporal variability in these coastal ocean processes was responsible for the asymmetric alongshelf spatial distribution patterns in the contaminated sediments deposited around the ocean outfall, and (3) whether the contaminated deposit was likely to be exposed, eroded, and cause heavily contaminated sediments to spread over a much larger region of the shelf.

The original research programs conducted in 1992-93 showed that near-bottom currents caused by surface waves resuspended fine material from the seabed off Palos Verdes (Noble and others, 2002 Wiberg and others, 2002). Given that near-bottom surface wave velocities were thought to have uniform amplitudes along the Palos Verdes shelf, it was known that resuspension from surface waves alone could not produce the asymmetric pattern in the along-shelf distribution of contaminated sediments around the outfall. However, because the mean near-bottom currents usually flowed upcoast, it was thought that they were the primary mechanism causing the fine contaminated materials to be preferentially deposited at sites upcoast and slightly offshore of the outfall. Researchers in this initial program could not determine whether spatial structures in the amplitudes of near-bottom currents associated with surface tides, internal tides, or internal bores could differentially resuspend and transport surficial sediments along the Palos Verdes shelf. This was in part because modern instruments, such as Acoustic Doppler Current Profilers (ADCPs), that monitor coastal ocean processes with the high vertical resolution necessary to measure these processes and the dense along-shelf sampling grids necessary to resolve along-shelf gradients in current amplitudes, were not available in the initial measurement program.

In 2000, LACSD began deploying the required dense array of moorings along the Palos Verdes shelf and over the northwestern portion of San Pedro Bay (fig. 1). At each site, a bottom platform that housed an ADCP and adjacent moorings that supported thermistor strings were placed on the seabed. These bottom platforms and moorings have collected vertical profiles of current and temperature data in the region continu- 
ously over the past few years. They are still collecting data at this time. In this report, we will use the data from the first 2 years of these deployments to determine (1) the spatial and temporal structures of the regional current field of surface tides, internal tides, and internal bores, (2) the mechanisms responsible for along-shelf gradients in tidal-period current amplitudes, (3) the ability of near-bottom currents associated with these phenomena to resuspend fine sediments, and (4) how the spatial structures associated with these phenomena are partly responsible for the asymmetrical spatial patterns found in the fine contaminated sediments in the region.

\section{Topographic Setting}

The shelf off the Palos Verdes peninsula is approximately $15 \mathrm{~km}$ long and less than $3 \mathrm{~km}$ wide (fig. 1). The cross-shelf slope of the seabed is 1 to 3 degrees, an angle that is critical for the generation of internal tides (fig. 3). The majority of the shelf is covered with a lens of fine material located generally offshore of the 30-m isobath and upcoast of the LACSD outfall (figs. 2 and 4). Slightly coarser sediments are found on the shelf downcoast of the outfall. Fine sediments are also draped over the shelf edge onto the continental slope. Many of these fine sediments are contaminated with DDT and its derivative products (Lee and others, 2002; Eganhouse and Pontolillo, 2000). This lens of fine contaminated material can be up to $60 \mathrm{~cm}$ thick, although the core of the most heavily contaminated sediments tends to be in the region surrounding the outfall and buried 10 $\mathrm{cm}$ or more below the seabed (fig. 5).

It is known from the field programs conducted in 1992-93 that near-bottom velocities could and did resuspend the fine sediments in this region. However, the complexity of the spatial patterns in the susceptibility to erosion of the local sediments

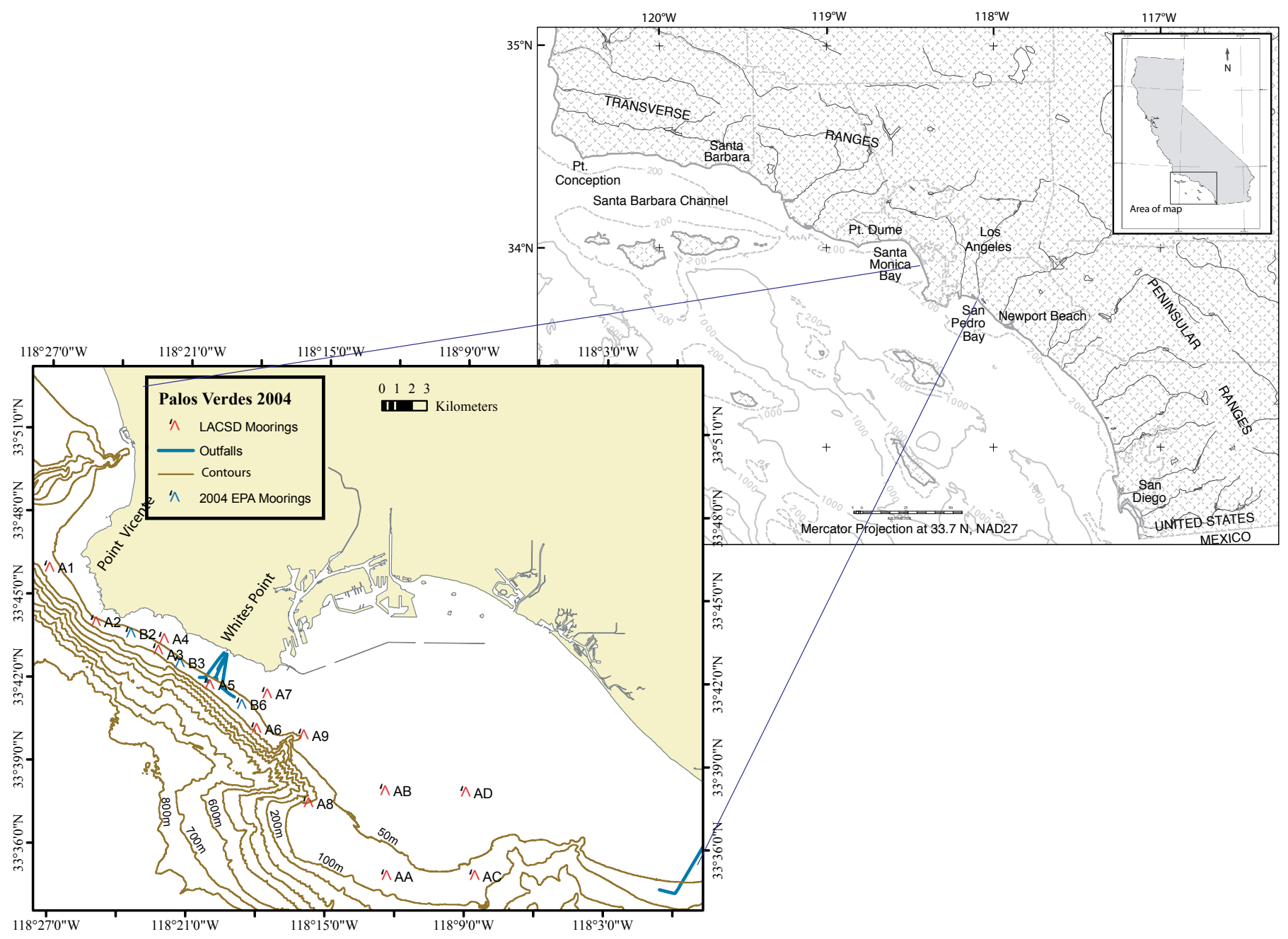

Figure 1. Location of mooring sites on the Palos Verdes and San Pedro shelves. Moorings $A 4, A 7, A 9, A B$, and $A D$ are deployed along the $35-m$ isobath. Moorings B2, B3, and B6 are deployed along the 60-m isobath. The remaining moorings are deployed along the 65-m isobath. LACSD moorings were deployed by the Los Angeles County Sanitation District; EPA moorings were deployed by the U.S. Environmental Protection Agency in conjunction with the U.S. Geological Survey and Science Applications International Corporation. 
was not understood until a program conducted in 2004 estimated the potential erodability of sediments (Murray and Chien, 2006). The estimates were based on (1) erodability measurements at 10 sites within and around the deposit of contaminated sediment on the Palos Verdes shelf and (2) the depth that a sediment profiling camera, which collected vertical profiles of sediments on the seabed at other sites (Rhoads and Germano, 1986; Science Applications International Corporation (SAIC), 2005a), penetrated into the sea floor. These measurements were used to generate a detailed map that shows how easily the sediments could be eroded (fig. 6). The most easily erodable sediments were found upcoast (northwest) of the outfall in water generally deeper than $30 \mathrm{~m}$, coincident with the position of the fine, generally contaminated sediment in the region (figs. 2 and 4). The sediments downcoast (southeast) of the outfall were coarser, less contaminated, and less erodable.

\section{Instrumented Arrays and Initial Data- Processing Procedures}

\section{Moored Arrays of Current, Temperature, and Pressure Data}

In the fall of 2000, LACSD deployed a primary array of moored instruments at nine locations along and just southeast of the Palos Verdes shelf (sites A1-A9) (figs. 1 and 3). These sites are either on or encompass the deposit of fine contaminated sediments discussed above. At each site, an upward-looking ADCP was deployed on the seabed to acquire vertical profiles of horizontal current velocity every $3 \mathrm{~m}$ in the water column (fig. 7). Adjacent to each ADCP,

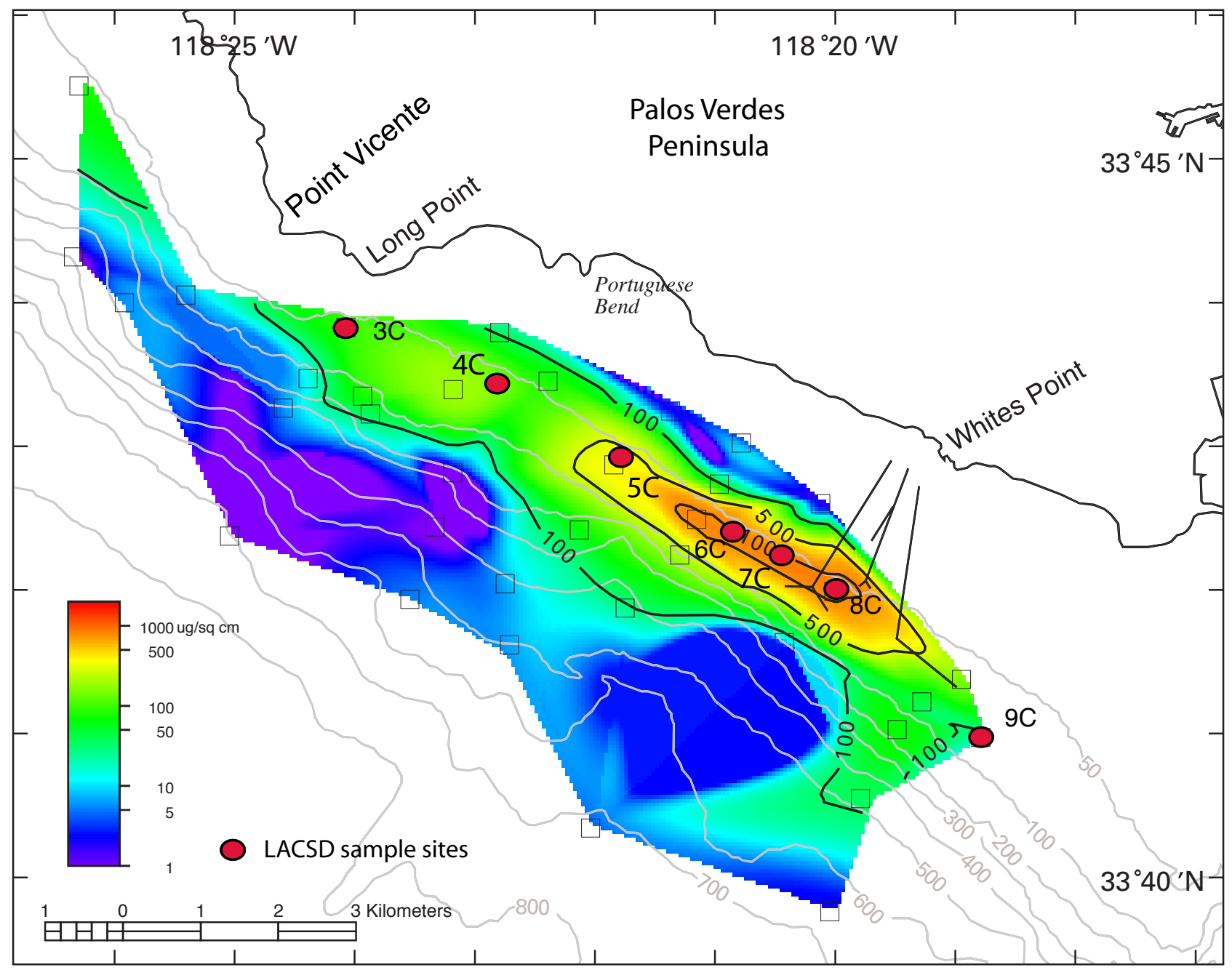

Figure 2. Map of contaminated lens of sediment off the Palos Verdes shelf, showing total mass of DDT per unit area. Figure adapted from Lee and others (2002). LACSD moorings were deployed by the Los Angeles County Sanitation District. 
separate moorings were deployed to acquire data on the vertical temperature structure of the water column using individual, internally recording temperature sensors separated by the same 3-m spacing as was used in the current profiles. All instruments in the array collected data at 15-minute intervals. All times are in Greenwich Mean Time (GMT or UTC).

Most of the moorings in the primary array were deployed along the $65-\mathrm{m}$ isobath, a depth just offshore of the core of the heavily contaminated sediment deposit (sites A1, A2, A3, A5, A6, and A8) (fig. 1). Additional moorings were deployed along the $35-\mathrm{m}$ isobath, along the inshore edge of the contaminated sediments (sites A4, A7, A9), allowing the monitoring of the local cross-shelf, as well as along-shelf transport patterns. One cross-shelf array was deployed on the contaminated deposit several kilometers northwest of the outfall (sites A3 and A4) (figs. 1, 2, and 3). The sediments at these sites are among the more easily eroded sediments in the region (fig. 6). A second cross-shelf array was deployed at sites A6 and A7, approximately $1-2 \mathrm{~km}$ downcoast of the contaminated deposit. Sediments in this region are coarser and much harder to erode. The data from this entire suite of moorings allows one to not only determine the spatial and temporal patterns for currents and bottom stresses in the region, but how these patterns relate to the relative erodability of local sediments.

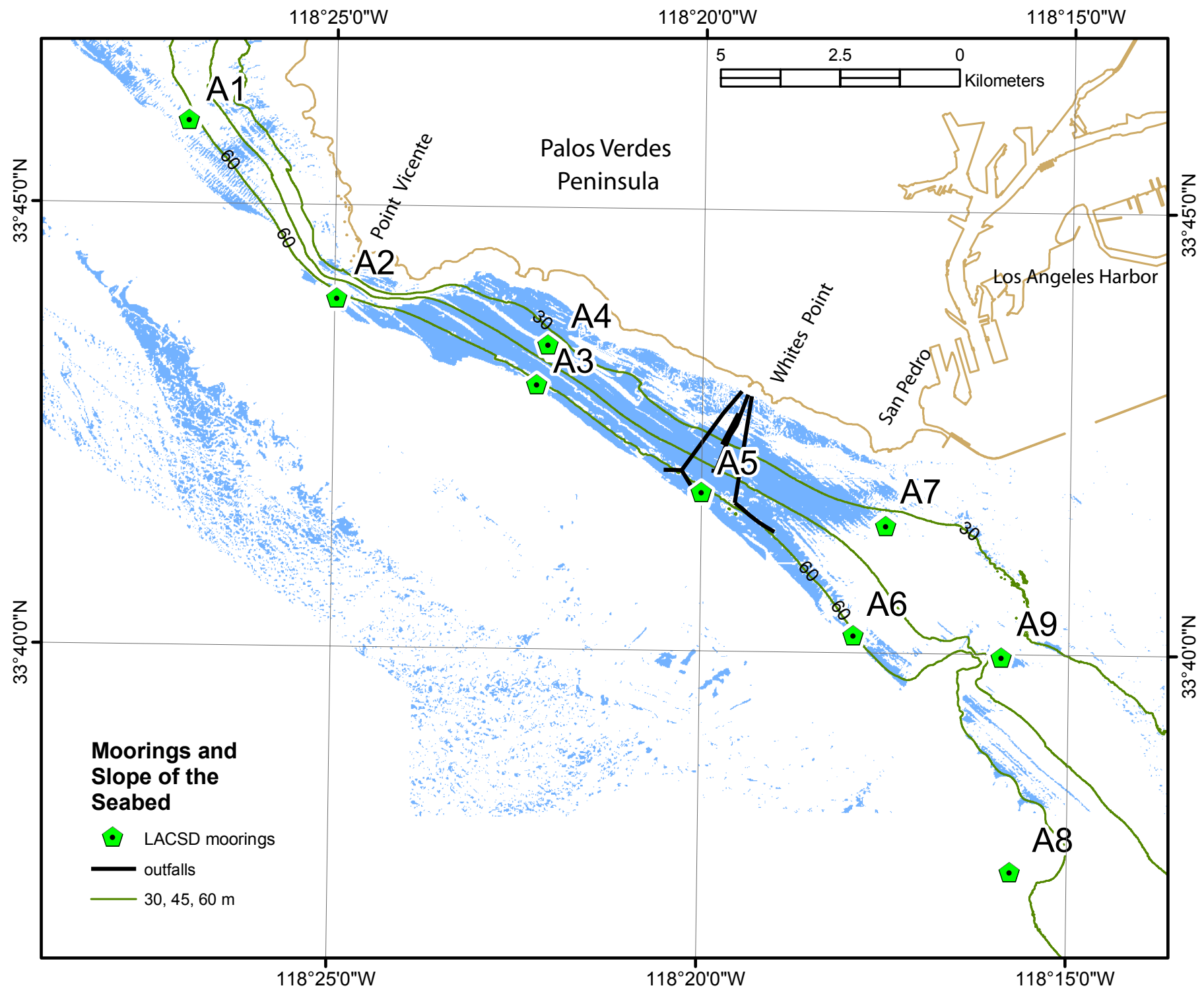

Figure 3. Cross-shelf angle of the seabed. The blue color shows the regions where the cross-shelf slope at the seabed is 1 to 3 degrees, a slope approximately critical for the generation of semidiurnal internal tides. LACSD moorings were deployed by the Los Angeles County Sanitation District. 
Approximately a year after the initial deployment of the primary array, LACSD deployed a similar set of instruments in a secondary array at four sites on the northwestern portion of the San Pedro shelf (sites AA-AD) (fig. 1). The sampling scheme was the same as in the primary array. Data from the current meters in the secondary array augmented our examination of the barotropic tidal currents in the region.

Near-bottom pressure sensors mounted on tripods resting on the seabed were deployed for 4 months in the late winter and early spring of 2004 by the USGS, Science Applications International Corporation (SAIC), and the EPA along the $60-\mathrm{m}$ isobath at sites B2, B3, and B6 (fig. 1) (SAIC, 2005a; Sherwood and others, 2002). Data from these near-bottom pressure sensors, together with concurrent sea-level measurements from Los Angeles Harbor, corrected for atmospheric pressure fluctuations, were used to determine the along-shelf structure of the tidal frequency sea-level fluctuations in the region.

\section{Initial Data-Processing Procedures}

Although nearly continuous records of currents were collected in the primary and secondary arrays (fig. $8 A$ ), some temporal gaps appear in the data records. The largest and most continuous data sets were collected by current meters deployed between May 2001 and May 2003. These are the primary data sets used in this paper. Generally high data returns were also found in the instruments deployed in the secondary and pressure arrays (figs. $8 A$ and $8 B$ ). Details of the field operations, instrument sampling schemes, and other aspects of the LACSD, USGS, and SAIC field programs are given in several reports about the Palos Verdes Flow Field Study (SAIC, 2004, 2005b; Sherwood and others, 2002).

Small temporal gaps in the current records from the ADCPs were filled by different numerical algorithms. Gaps of less than an hour were filled by linear interpolation. Gaps

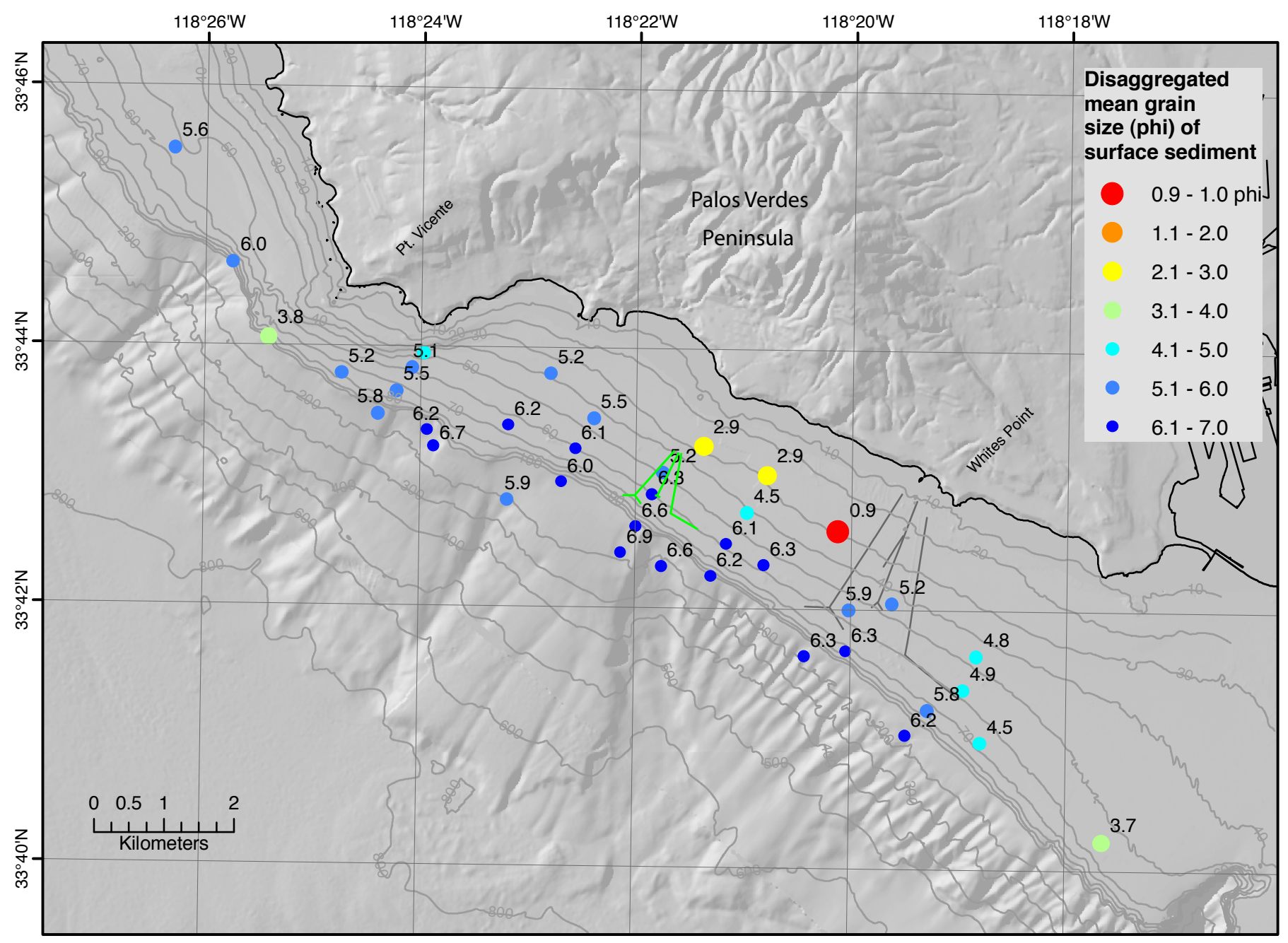

Figure 4. Disaggregated mean grain size of surficial sediment on the Palos Verdes shelf based on data collected by the U.S. Geological Survey in July 1992. Figure adapted from Drake and others (2002). Finer sediments have larger phi sizes. 
of one or two days were usually filled spectrally using an algorithm that attempts to preserve the spectral content, tidal phase, and vertical coherence of the original data (Anderson, 1974). Some longer gaps found in current records that moni- tored the near-surface flow field were filled with a record of the currents measured just $3 \mathrm{~m}$ below the gap, suitably scaled for the average change in current amplitude with depth. Otherwise, the gaps in the record were not filled, and, generally,

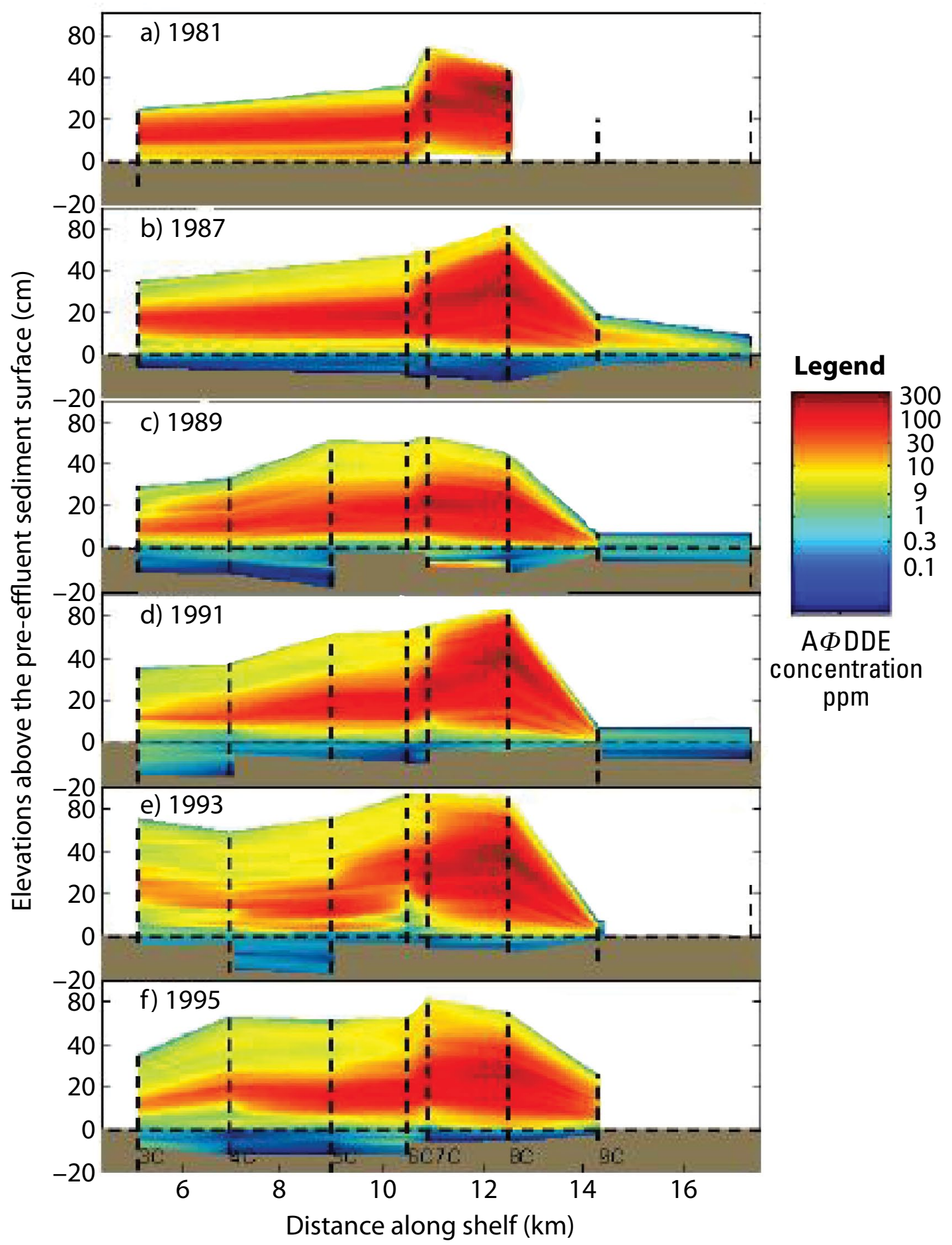

Figure 5. Vertical profiles and evolution of the DDT deposited on the Palos Verdes shelf along the 60-m isobath. The location of cores (depicted by vertical dashed lines in this figure) are shown in figure 2. Figure adapted from Lee and others (2002). 
this near-surface current record was deleted from the suite of analyzed current records (table 1). These data-processing procedures resulted in the creation of continuous current records over one to two years.

The east and north (along- and cross-shelf) current components for each ADCP were depth-averaged, then low-pass-filtered to generate a subtidal record of the average current speed and direction at each site. These depth-averaged, subtidal current records were used to determine the principal axis (prominent direction) of the local along-shelf current at each site (fig. 9). In general, the local along-shelf currents flow parallel to the local isobaths. Positive along-shelf cur-

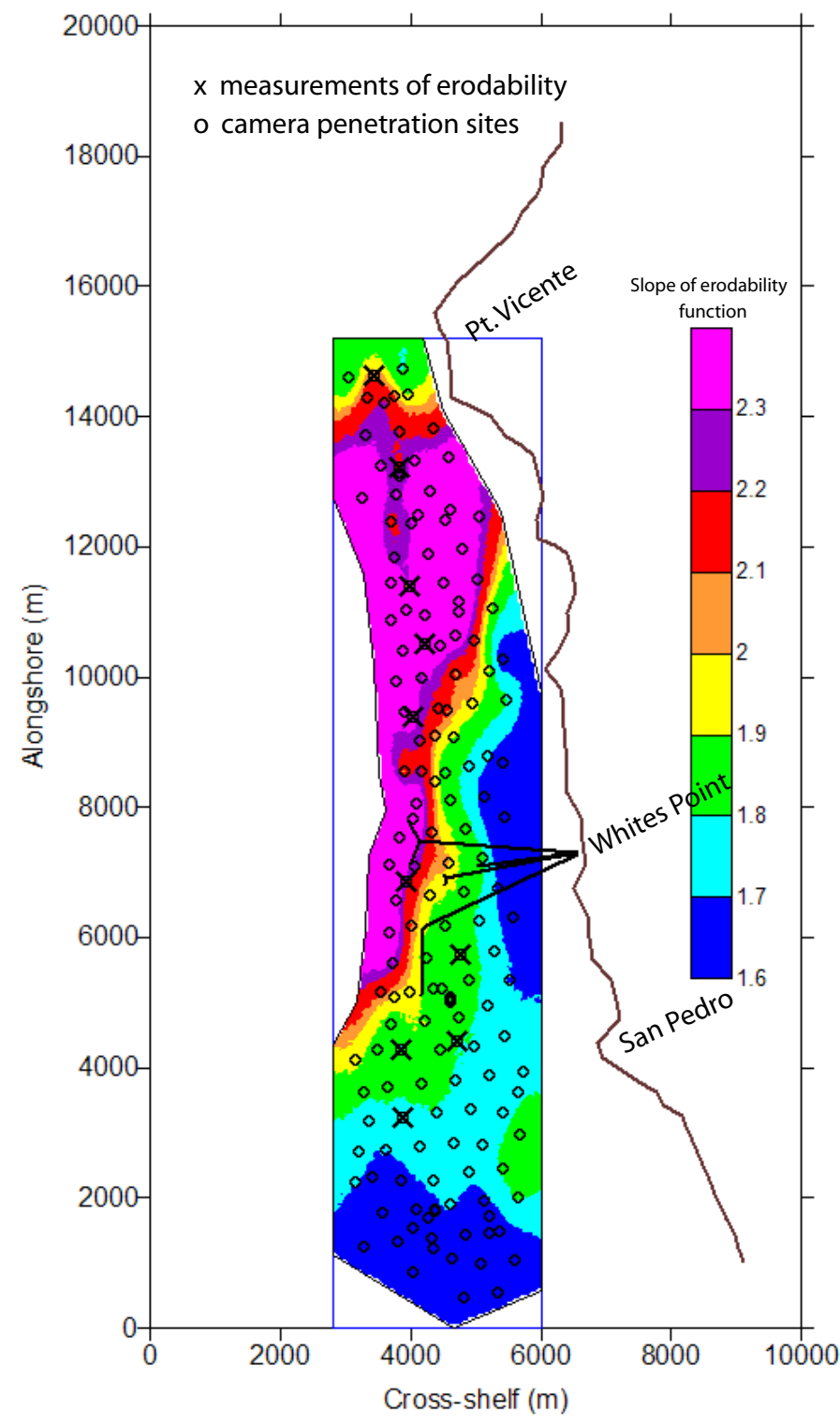

Figure 6. Map of slope of the erodability function that indicates the potential erodability of sediments at sites within and around the de posit of contaminated sediment (Murray, 2006). Blue (red) denotes regions of low (high) potential erodability. rents flow upcoast (toward the northwest). Positive cross-shelf currents are directed 90 degrees to the right of the along-shelf currents; they flow toward the coast. The individual current records were rotated into along- and cross-shelf orientation. Hence, we have both east/north and along/cross-shelf orientations for each current record.

It was much more difficult to obtain continuous data from the temperature arrays because instruments deployed to monitor near-surface temperature tended to be struck by ships, and thus failed. The deeper temperature sensors provided more continuous records, even though occasionally sensors failed to record data. Hence, many of the temperature records have data gaps; large gaps of two days or more were not filled.

One pressure sensor was recovered and redeployed twice during the measurement program. The 2-day data gaps in this pressure record were filled spectrally. The other pressure sensors recorded continuous data for the duration of their deployments.

\section{Current Patterns on the Palos Verdes Shelf}

\section{Mean Currents}

The depth-averaged mean currents at sites over the deposit flowed primarily upcoast toward the northwest (sites A1-A5) (fig. 10). The mean flow directions were more variable at sites southeast of the outfall; the depth-averaged currents along the $65-\mathrm{m}$ isobath tended to flow upcoast while those along the inner shelf tended to flow downcoast. Overall, the amplitudes of the mean currents were small; depth-averaged current speeds were usually less than $4 \mathrm{~cm} / \mathrm{s}$ (table 2).

The dominant flow direction for mean currents near the seabed, the steady portion of the current field that carries resuspended sediments, was upcoast at most sites in the area, even at sites southeast of the deposit (fig. 10, table 2). There was a slight tendency for the near-bottom mean currents to flow off as well as along the shelf, especially at sites along the 65-m isobath. Mean current amplitudes near the seabed tended to be as large, or sometimes slightly larger than, the mean current averaged over the water column. However, the amplitudes of these near-bottom currents were still fairly small. These mean currents could carry material resuspended near the seabed along and possibly off the $15-\mathrm{km}$ length of the Palos Verdes shelf in 3 to 5 days.

\section{Tidal Current Patterns}

\section{General Characteristics of Surface and Internal Tides}

Tidal currents are fundamentally caused by the gravitational attractions between the rotating Earth and its position 
relative to the Moon and Sun. The astronomical tidal force has a wide range of frequencies; tidal periods range from hours to many years. Because the moon is much closer to the Earth, it tends to have a stronger gravitational, or astronomical, force on water level (and subsequently on the tidal currents) in the ocean than does the sun. Based on the strength of the astronomical forcing, the largest tidal constituent is the semidiurnal principal lunar tide, $\mathrm{M}_{2}$, which has a period of 12.42 hours. The other large semidiurnal constituent is the principal solar tide, $\mathrm{S}_{2}$, which has a period of 12.00 hours. The diurnal tides, which are the other dominant astronomical tidal constituents, are the principal lunar diurnal tide, $\mathrm{O}_{1}$, with a period of 25.82 hours, and the luni-solar diurnal tide, $\mathrm{K}_{1}$, with a period of 23.93 hours.

There are many other tidal constituents, including ones with frequencies in the diurnal and semidiurnal bands. How- ever, many of these tidal constituents have weak astronomical forcing and are rarely monitored in coastal ocean currents. It should be noted that the relative amplitude of local tidal-current constituents may not reflect the strength of the astronomical forcing because many features in the ocean, such as the shape of ocean basins, affect how currents and sea level respond to tidal forcing. This is particularly true for the relative amplitude of tidal currents on continental shelves because they do not respond directly to the astronomical tidal forcing. Instead, tidal currents on the shelf are driven indirectly by tidal currents and sea-level fluctuations in the adjacent deep ocean basins.

Tidal currents tend to be classified into two types of flows. The barotropic, or surface, tidal currents are oscillating flows at tidal periods that have a uniform amplitude with depth. These are usually the only tidal currents present in a body of

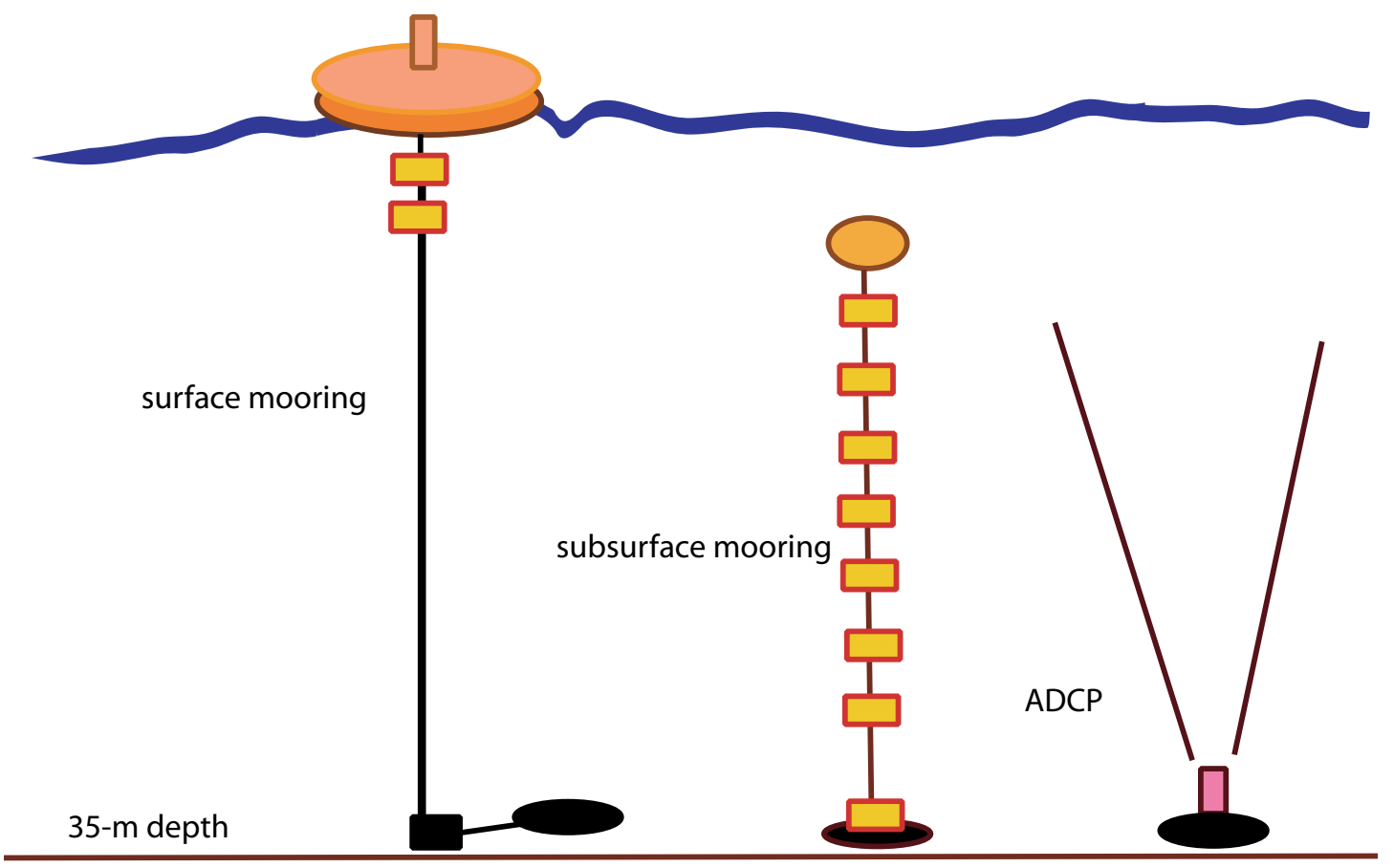

thermistors

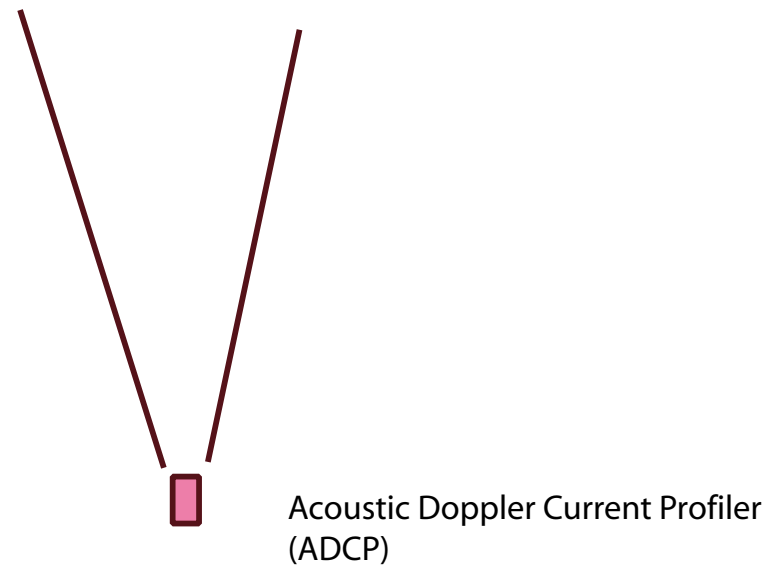

Figure 7. Mooring diagram depicting site $A 4$, showing current (ADCP) and temperature monitoring instruments. 


\section{Bottom Mounted ADCP Moorings}

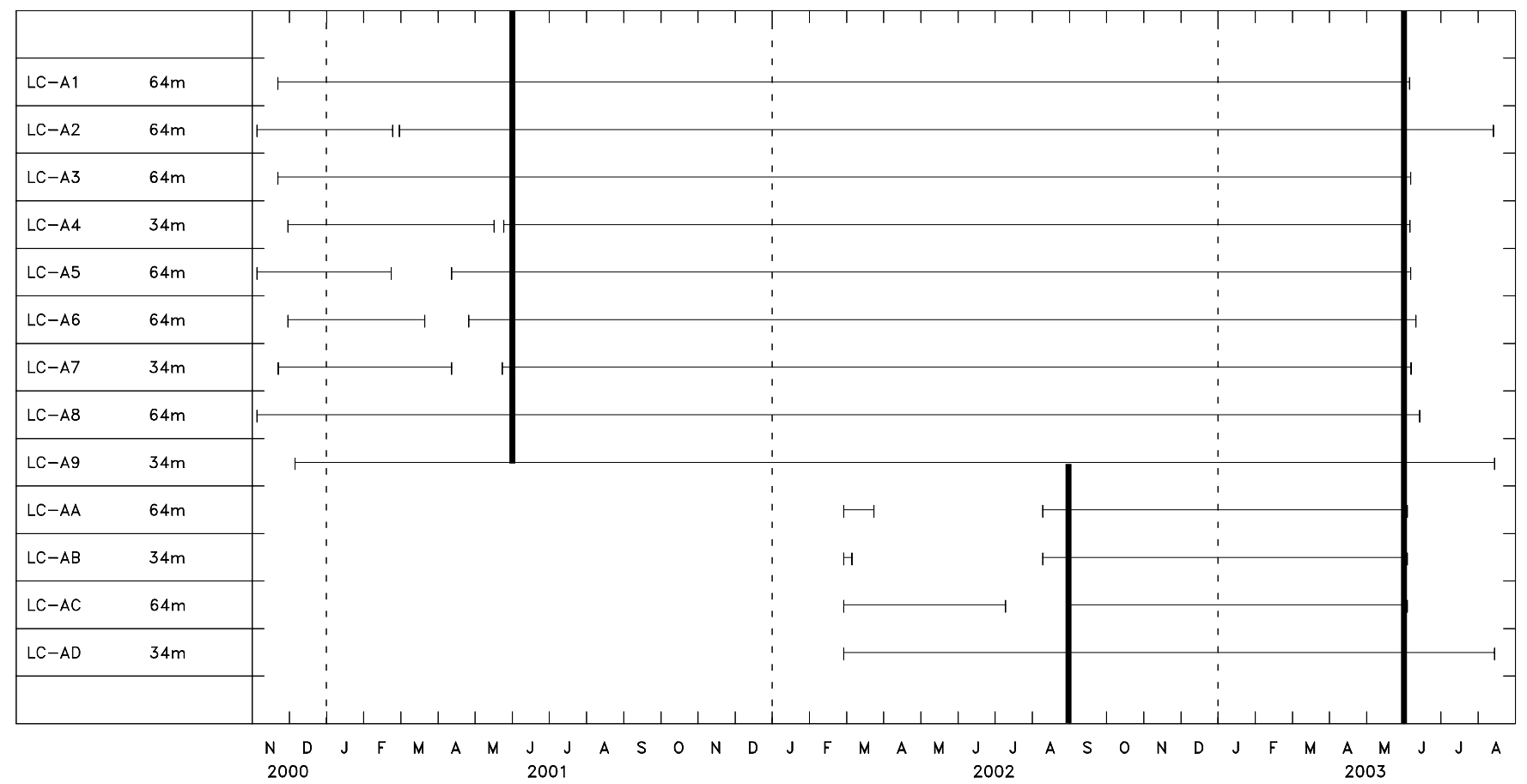

Figure 8A. Timelines showing dates when data exists for ADCP instruments. Dark lines show the dates of the primary and secondary data sets used in this report. Figure adapted from Science Applications International Corporation (2004).

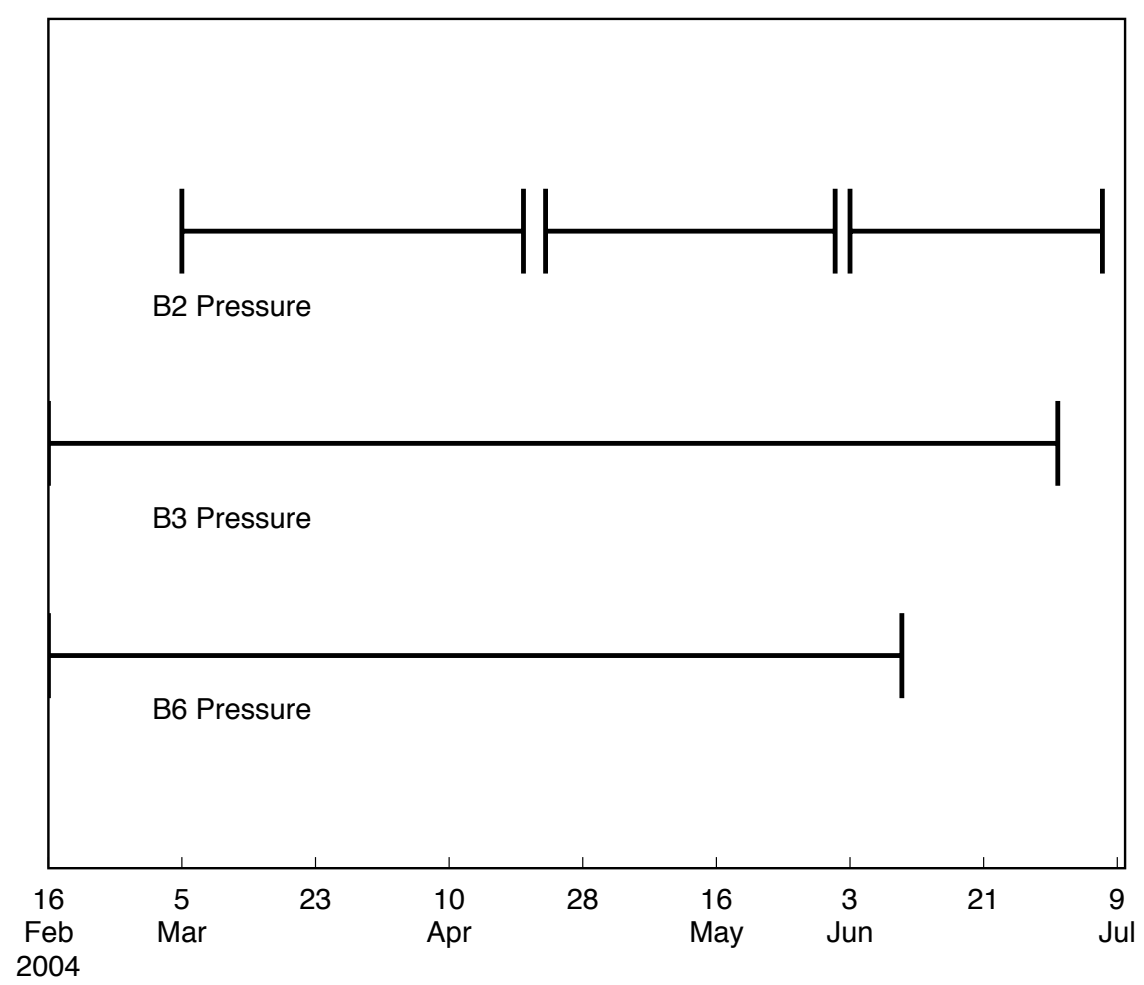

Figure 8B. Timelines showing dates for bottom pressure measurements on the Palos Verdes shelf. B2, B3, and B6 indicate pressure measuring instrument stations (fig. 1). 
Table 1. Depths in meters of the current bins at all stations in the primary and secondary arrays.

\begin{tabular}{|c|c|c|c|c|c|c|c|c|c|c|c|c|c|c|c|c|c||}
\hline Bin No. & A1 & A2 & A3 & A5 & A6 & A8 & AA & AC & Bin No. & A4 & A7 & A9 & AB & AD \\
\hline \hline
\end{tabular}

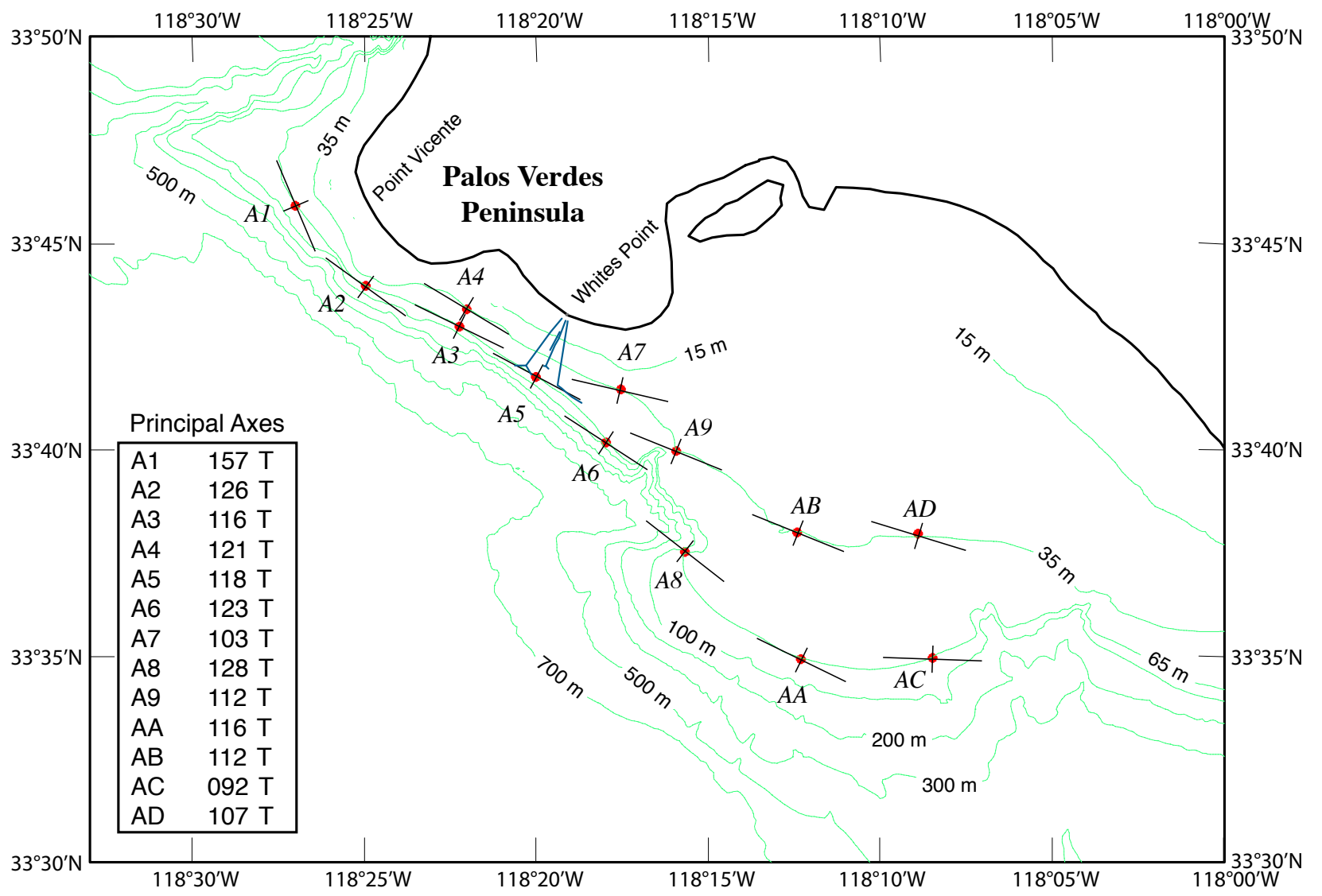

Figure 9. Principal axes of alongshore currents. Figure adapted from Science Applications International Corporation (2004). 
Table 2. Mean along- and cross-shelf current amplitudes averaged over the entire water column and 3 meters above the seabed (mab); error bars are at the 95 percent confidence level.

\begin{tabular}{|c|c|c|c|c|}
\hline \multirow[t]{2}{*}{ Station } & $\begin{array}{l}\text { Along-shelf } \\
\text { depth-averaged } \\
\text { mean flow }\end{array}$ & $\begin{array}{c}\text { Along-shelf } \\
\text { mean flow } \\
3 \text { mab }\end{array}$ & $\begin{array}{l}\text { Cross-shelf } \\
\text { depth-averaged } \\
\text { mean flow }\end{array}$ & $\begin{array}{c}\text { Cross-shelf } \\
\text { mean flow } \\
3 \text { mab }\end{array}$ \\
\hline & \multicolumn{4}{|c|}{$\mathrm{cm} / \mathrm{s}$} \\
\hline A1 & $1.0 \pm 1.4$ & $2.7+0.7$ & $-0.9+0.2$ & $-1.0 \pm 0.2$ \\
\hline $\mathrm{A} 2$ & $5.0+1.4$ & $4.5+0.8$ & $0.4+0.3$ & $-0.0+0.2$ \\
\hline A3 & $3.1+0.9$ & $1.7+0.6$ & $0.7+0.1$ & $-0.5+0.2$ \\
\hline A4 & $2.8+0.9$ & $2.7+0.6$ & $0.4+0.1$ & $-0.6 \pm 0.2$ \\
\hline A5 & $1.8+1.0$ & $1.2+0.7$ & $0.9+0.2$ & $-0.1+0.2$ \\
\hline A6 & $1.1+1.1$ & $3.3+0.5$ & $1.0 \pm 0.3$ & $-2.1+0.3$ \\
\hline A7 & $-2.3+1.4$ & $0.4+0.6$ & $-0.3+0.3$ & $-0.6+0.3$ \\
\hline A8 & $0.8+1.2$ & $3.1+0.5$ & $0.7+0.4$ & $-0.6+0.4$ \\
\hline A9 & $-2.5+1.5$ & $1.3+0.7$ & $1.8+0.4$ & $0.2+0.4$ \\
\hline
\end{tabular}

water that has a constant density, and are the tidal currents associated with the tidal oscillations at sea level. Internal tides, which contain much of the vertical structure present in the tidal currents, can only exist if there are vertical gradients in the temperature and/or salinity of the water column. Because vertical density gradients are almost always present over the Palos Verdes shelf, internal tides can be present in all seasons. Theoretically, the depth average of an internal tidal current is very close to (but not identical to) zero. The first mode for internal tides, which is usually the most energetic mode, has surface currents that flow opposite to currents near the seabed.

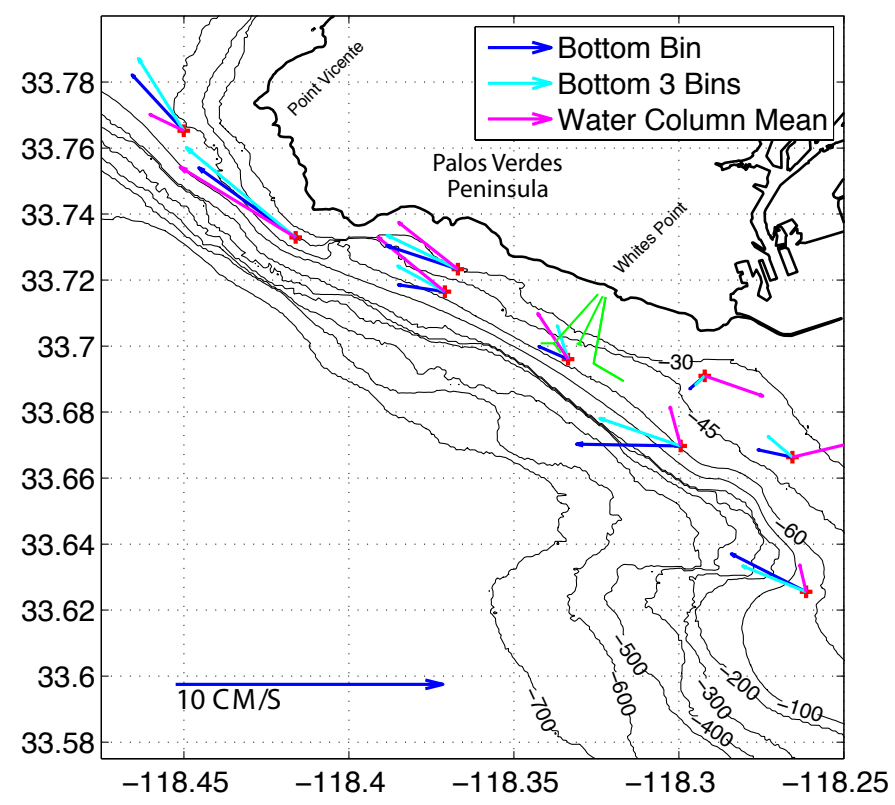

Figure 10. Direction of mean current flows at the primary measurement sites in the moored array.
There is no net horizontal transport associated with either a perfectly linear surface or internal tide because the currents just oscillate back and forth along and/or across the shelf. If settling is ignored, a suspended particle will move from, then return to, its original position under a spatially homogeneous linear tidal-current oscillation. Net transport can occur if nonlinear processes alter a tidal current and cause one direction of a fluctuating flow field to be larger or last longer than the other. These asymmetric oscillating currents can be found in an internal tide that shoals as it propagates into shallow water or in an internal tide that transitions into an internal bore. A fully developed internal bore actually loses one-half of the typical tidal oscillation. Currents near the seabed move from a velocity near zero to a strong offshore flow, then return back to zero. There is no compensating onshore flow. Simultaneously, currents in the surface layers move from zero to an onshore flow, and return back to zero. Again, there is no compensating offshore flow. Hence, nonlinear internal tides and bores cause a vertically sheared net transport of suspended material in the coastal ocean.

\section{Barotropic Tides}

\section{Temporal Variations in Barotropic Tidal Currents}

The hour-averaged current records measured every 3 $\mathrm{m}$ in the water column during the 2-year time period in the primary array (sites A1-A9) were depth-averaged in order to generate one depth-mean current record at each site. Similar depth-mean current records were generated for the four stations that collected data for only three-quarters of a year in the secondary array (sites AA-AD). The barotropic tidal-current characteristics were calculated from these depth-mean current 
Table 3. Temporal variability in the amplitude of the principal diurnal and semidiurnal barotropic tidal currents.

[Tidal frequencies are labeled $\mathrm{O}_{1}$ (diurnal) and $\mathrm{M}_{2}$ (semidiurnal). The reference barotropic tidal-current amplitude at each site is the size of the semimajor axis of the tidal constituent calculated using the entire 2-year (739-day) common record length in the primary array (figure $7 A$ ). The amplitude of each constituent of the barotropic tide was also calculated using sucessive record lengths of 1 year, 183-day and 3-month durations. The range in each set of record lengths is defined as half the difference between the amplitude of the largest and smallest tidal current measured in that set of shorter records divided by the reference tidal amplitude. Pressure records indicate that changes in tidal amplitudes due to variation in the nodal correction are minimal. Station locations along the $35-\mathrm{m}$ isobath are in bold type]

$\mathbf{O}_{1}$

\begin{tabular}{|c|c|c|c|c||}
\hline \hline Station & $\begin{array}{c}\text { Reference } \\
\text { barotropic tidal } \\
\text { current } \\
\text { amplitude }\end{array}$ & $\begin{array}{c}\text { Range for a } \\
\text { record length of } \\
1 \text { year }\end{array}$ & $\begin{array}{c}\text { Range for a } \\
\text { record length of } \\
183 \text { days }\end{array}$ & $\begin{array}{c}\text { Range for a } \\
\text { record length of } \\
3 \text { months }\end{array}$ \\
\hline A1 & 2.5 & $6 \%$ & $15 \%$ & $26 \%$ \\
\hline A2 & 3.6 & $4 \%$ & $8 \%$ & $15 \%$ \\
\hline A3 & 2.5 & $2 \%$ & $15 \%$ & $28 \%$ \\
\hline A4 & 2.7 & $7 \%$ & $19 \%$ & $39 \%$ \\
\hline A5 & 2.3 & $2 \%$ & $2 \%$ & $13 \%$ \\
\hline A6 & 2.0 & $8 \%$ & $17 \%$ & $30 \%$ \\
\hline A7 & 2.5 & $8 \%$ & $35 \%$ & $50 \%$ \\
\hline A8 & 1.2 & $8 \%$ & $22 \%$ & $21 \%$ \\
\hline A9 & 1.7 & $9 \%$ & $32 \%$ & $44 \%$ \\
\hline
\end{tabular}

$\mathbf{M}_{2}$

\begin{tabular}{|c|c|c|c|c||}
\hline Station & $\begin{array}{c}\text { Reference } \\
\text { barotropic tidal } \\
\text { current } \\
\text { amplitude }\end{array}$ & $\begin{array}{c}\text { Range for a } \\
\text { record length of } \\
1 \text { year }\end{array}$ & $\begin{array}{c}\text { Range for a } \\
\text { record length of } \\
183 \text { days }\end{array}$ & $\begin{array}{c}\text { Range for a } \\
\text { record length of } \\
3 \text { months }\end{array}$ \\
\hline \hline A1 & 3.1 & $14 \%$ & $22 \%$ & $69 \%$ \\
\hline A2 & 1.5 & $33 \%$ & $44 \%$ & $183 \%$ \\
\hline A3 & 2.5 & $12 \%$ & $40 \%$ & $74 \%$ \\
\hline A4 & 2.5 & $18 \%$ & $48 \%$ & $86 \%$ \\
\hline A5 & 5.3 & $3 \%$ & $14 \%$ & $18 \%$ \\
\hline A6 & 6.4 & $6 \%$ & $13 \%$ & $20 \%$ \\
\hline A7 & 10.1 & $2 \%$ & $11 \%$ & $18 \%$ \\
\hline A8 & 5.7 & $6 \%$ & $21 \%$ & $28 \%$ \\
\hline A9 & 7.5 & $3 \%$ & $20 \%$ & $41 \%$ \\
\hline
\end{tabular}

records at each site using the Foreman tidal programs (Foreman, 1977; 1978).

A current record averaged over a dense vertical grid should give a stable, reasonably close estimate of the actual barotropic tidal current because its amplitude is, theoretically, constant over time. In order to determine if the amplitudes of the barotropic tidal currents were indeed stable, the tidalcurrent amplitudes in the primary array were calculated over several different lengths of records. Tidal-current constituents were calculated from successive 3-month, 6-month, and 1-year segments in the common 2-year data set for the $\mathrm{O}_{1}$ and $\mathrm{M}_{2}$ tides (table 3 ). We chose to determine the stability for these frequencies because, unlike the $\mathrm{K}_{1}$ and $\mathrm{S}_{2}$ tides, pressure records confirmed that there were no other barotropic tidal constituents that were close enough in frequency and that had a large enough amplitude to cause an apparent temporal variation in the measured tidal currents by beating against the primary constituent.

In the shortest segments of records, measured amplitudes for the presumably barotropic tidal currents had quite large ranges (table 3). Diurnal tidal-current amplitudes generally varied by 0.5 to $0.8 \mathrm{~cm} / \mathrm{s}$, which is around $20-40$ percent of the mean, in record segments that were 3 months long. Amplitude variations in these short records were even larger for the semidiurnal tidal currents; they were generally around 1.0 to 2.8 $\mathrm{cm} / \mathrm{s}$, or 20 percent to more than 100 percent of the mean.

Tidal-current amplitudes were more stable in the longer sections of record. When record lengths were at least a year 
Table 4. Amplitude of sea level fluctuations in the diurnal and semidiurnal bands.

[Tidal frequencies are labeled $\mathrm{O}_{1}$ and $\mathrm{K}_{1}$ (diurnal) and $\mathrm{M}_{2}$ and $\mathrm{S}_{2}$ (semidiurnal). Tidal amplitudes were calculated for a common 3-month time period for all $\mathrm{B}$ stations. Tidal amplitudes at Los Angeles (LA) harbor were calculated using a 2-year record. The phase changes among the $\mathrm{B}$ stations were generally too small to be statistically significant]

\begin{tabular}{||l|c|c|c|c|c|c|c|c||}
\hline \hline Station & \multicolumn{2}{|c|}{$\mathrm{O}_{1}$} & \multicolumn{2}{c|}{$\mathrm{K}_{1}$} & \multicolumn{2}{c|}{$\mathrm{M}_{2}$} & \multicolumn{2}{c||}{$\mathrm{S}_{2}$} \\
\hline & Amplitude & Phase & Amplitude & Phase & Amplitude & Phase & Amplitude & Phase \\
\hline & $\mathrm{cm}$ & degrees & $\mathrm{cm}$ & degrees & $\mathrm{cm}$ & degrees & $\mathrm{cm}$ & degrees \\
\hline \hline B2 & 22 & 188 & 34 & 196 & 51 & 139 & 20 & 130 \\
\hline B3 & 22 & 190 & 31 & 198 & 51 & 143 & 23 & 133 \\
\hline B6 & 22 & 190 & 31 & 197 & 51 & 142 & 23 & 133 \\
\hline $\begin{array}{l}\text { LA } \\
\text { harbor }\end{array}$ & 22 & 193 & 34 & 208 & 51 & 146 & 20 & 141 \\
\hline \hline
\end{tabular}

long, both the diurnal and semidiurnal tidal-current amplitudes were usually within 10 percent of the mean, except at stations where the tidal-current amplitudes were relatively weak and therefore subject to larger percentage variations if there were small changes in measured amplitudes.

The characteristics of the barotropic tide discussed in subsequent sections of this report are calculated using the longest available records at each site. Hence, the measured tidal-current characteristics are a close representation of the actual barotropic tidal currents at sites in the primary array. The characteristics of the measured barotropic currents in the secondary array are probably within 10 percent of the actual barotropic tidal currents because they were calculated from records three-quarters of a year long.

\section{Characteristics of Measured and Modeled Barotropic Tides}

The amplitudes of tidal fluctuations in sea level were calculated using two years of tide-gauge observations from Los Angeles Harbor and several months of near-bottom pressure measurements made along the $60-\mathrm{m}$ isobath off the Palos Verdes peninsula (fig. 1). The semidiurnal $\mathrm{M}_{2}$ tide was the dominant tidal constituent; its amplitude was 50 $\mathrm{cm}$ (table 4). The diurnal $\mathrm{K}_{1}$ tide was the next largest, with an amplitude just over $30 \mathrm{~cm}$. The diurnal and semidiurnal sea-level fluctuations did not have a noticeable along-shelf variation in either the amplitude or phase of the tide. Fluctuations in Los Angeles Harbor were similar to those at station B2, the measurement site furthest upcoast. The relative amplitudes among the various other constituents was not a function of location (table $6 \mathrm{~A}$ ).

The barotropic tidal currents in this region are a mixture of diurnal and semidiurnal tidal constituents, similar to the pattern found in tidal sea-level fluctuations (table 5). The principal semidiurnal tidal current, $\mathrm{M}_{2}$, tends to be the largest tidal constituent at sites near and southeast of the LACSD outfall (tables 5 and $6 B$ ). The semidiurnal tidal flows are aligned primarily along the isobaths, with relatively narrow tidal-current ellipses. Currents flowing parallel to the minor axis of the tidal ellipse generally have amplitudes less than 20 percent of those flowing parallel to the major axis of the ellipse. The phases of the principal tidal-current constituents suggests that they are all propagating upcoast, toward the northwest (table 5).

However, contrary to the fairly uniform along-shelf amplitudes in the tidal sea-level fluctuations, the most notable feature in the tidal currents along the Palos Verdes and northern San Pedro shelves is that they have a distinct change in amplitude with location. Diurnal current amplitudes increased by 60 to 70 percent as they transition from the relatively wide San Pedro shelf to the narrower Palos Verdes shelf (table 5). The spatial structure in the semidiurnal current field is more complex. Semidiurnal $\mathrm{M}_{2}$ tidal-current speeds on the relatively broad San Pedro shelf were generally around $5 \mathrm{~cm} / \mathrm{s}$ (table 5 and fig. 11). Semidiurnal $\mathrm{M}_{2}$ tidal-current amplitudes increased in the transition zone between the San Pedro and Palos Verdes shelves (sites A6, A7, and A9). Here, current speeds were 7 to $10 \mathrm{~cm} / \mathrm{s}$. Semidiurnal tidal-current speeds were much smaller over the Palos Verdes shelf itself; $M_{2}$ tidal currents were less than $3 \mathrm{~cm} / \mathrm{s}$ at sites over the northwestern portion of the deposit (sites A2, A3, and A4). This reduction in amplitude was most noticeable along the $35-\mathrm{m}$ isobath, where $\mathrm{M}_{2}$ tidal currents were reduced from $10 \mathrm{~cm} / \mathrm{s}$ at site $\mathrm{A} 7$ to less than $3 \mathrm{~cm} / \mathrm{s}$ at site $\mathrm{A} 4$.

The different spatial structures in the diurnal and semidiurnal currents affect the ratios of their amplitudes with location. On the northwestern portion of the San Pedro shelf (sites AA-AD), $\mathrm{M}_{2}$ was stronger than $\mathrm{K}_{1}$ by more than was predicted from the sea-level fluctuations (tables $6 A$ and $B$ ). $\mathrm{M}_{2}$ tidal currents were even more dominant in the transition region between the two shelves because the semidiurnal current amplitudes increased rapidly in this region. However, over the northern portion of the Palos Verdes shelf, upcoast of the outfall, diurnal currents dominated because the semidiurnal current amplitudes were relatively small.

The spatial patterns in both diurnal and semidiurnal currents are consistent within a frequency band. The ampli- 
Table 5. Barotropic tidal current characteristics calculated using records that are 739 days long (sites A1-A9) and records that are 277 days long (sites AA-AD).

[Tidal frequencies are labeled $\mathrm{Q}$ and $\mathrm{K}_{1}$ (diurnal) and $\mathrm{M}_{2}$ and $\mathrm{S}_{2}$ (semidiurnal). The inclination of the major axis of the tidal current ellipse is counterclockwise from the local along-shelf orientation. If a phase at a station upcoast of (northwest of) another station is larger than that at the downcoast station, then the tide is propagating to the northwest. Note that in the semidiurnal band, the phases of the two most northwestern stations are modulo 360]

$\mathbf{O}_{1}$

\begin{tabular}{|c|c|c|c|c||}
\hline Station & $\begin{array}{c}\text { Major axis } \\
\text { current }\end{array}$ & $\begin{array}{c}\text { Minor axis } \\
\text { current }\end{array}$ & Inclination & Phase \\
\hline & $\mathrm{cm} / \mathrm{s}$ & $\mathrm{cm} / \mathrm{s}$ & degrees & degrees \\
\hline \hline A1 & 2.5 & 0.2 & 3 & 207 \\
\hline A2 & 3.6 & 0.1 & -3 & 175 \\
\hline A3 & 2.5 & 0.1 & -5 & 165 \\
\hline A4 & 2.7 & 0.0 & -4 & 162 \\
\hline A5 & 2.3 & 0.2 & -4 & 149 \\
\hline A6 & 2.0 & 0.1 & -7 & 132 \\
\hline A7 & 2.5 & 0.2 & -20 & 129 \\
\hline A8 & 1.2 & 0.0 & -14 & 125 \\
\hline A9 & 1.7 & 0.1 & -16 & 11 \\
\hline AA & 1.8 & 0.1 & -22 & 106 \\
\hline AB & 1.7 & 0.5 & -40 & 116 \\
\hline AC & 1.2 & 0.1 & -33 & 93 \\
\hline AD & 1.6 & 0.2 & & \\
\hline \multicolumn{2}{|l}{} & & & 129 \\
\hline
\end{tabular}

$\mathbf{K}_{1}$

\begin{tabular}{||c|c|c|c|c||}
\hline Station & $\begin{array}{c}\text { Major axis } \\
\text { current } \\
\mathrm{cm} / \mathrm{s}\end{array}$ & $\begin{array}{c}\text { Minor axis } \\
\text { current }\end{array}$ & Inclination & Phase \\
\hline \hline A1 & 3.9 & 0.6 & degrees & degrees \\
\hline A2 & 5.8 & 0.4 & 3 & 230 \\
\hline A3 & 3.9 & 0.3 & -4 & 195 \\
\hline A4 & 4.7 & 0.1 & -7 & 174 \\
\hline A5 & 3.7 & 0.6 & -6 & 168 \\
\hline A6 & 3.1 & 1.1 & -4 & 154 \\
\hline A7 & 4.2 & 0.8 & -10 & 143 \\
\hline A8 & 2.3 & 0.2 & -1 & 123 \\
\hline A9 & 2.6 & 0.7 & -12 & 139 \\
\hline AA & 2.6 & 0.0 & -20 & 133 \\
\hline AB & 2.6 & 0.7 & -25 & 114 \\
\hline AC & 1.9 & 0.2 & -32 & 98 \\
\hline AD & 2.2 & 0.7 & -47 & 108 \\
\hline \multicolumn{2}{|l|}{} \\
\hline
\end{tabular}

tude ratios between $\mathrm{O}_{1}$ and $\mathrm{K}_{1}$, or between $\mathrm{M}_{2}$ and $\mathrm{S}_{2}$, are similar to the ratios found in sea level and do not change with station location (tables $6 A$ and $B$ ). The relatively constant amplitude ratios within each tidal band suggest that the spatial patterns are persistent and affect all tidal currents within each band.

The Advanced Circulation (ADCIRC) depth-averaged tidal model for the entire Pacific coast (Baja California to Alaska) was used to obtain the predicted characteristics of the barotropic semidiurnal $\mathrm{M}_{2}$ tide in this region (Spargo and others, 2004). The model has a roughly $1-\mathrm{km}$-grid resolution in the Palos Verdes region.

Model predictions of semidiurnal $\mathrm{M}_{2}$ sea-level fluctuations were similar to the measured (table $7 A$ ). Both modeled and measured sea-level fluctuations had relatively constant amplitudes and small phase changes along both the San Pedro and Palos Verdes shelves; $\mathrm{M}_{2}$ sea-level amplitudes were around $50 \mathrm{~cm}$ over the entire region. 
Table 5. Barotropic tidal current characteristics calculated using records that are 739 days long (sites A1-A9) and records that are 277 days long (sites AA-AD) - Continued.

$\mathbf{M}_{2}$

\begin{tabular}{|c|c|c|c|c|}
\hline Station & $\begin{array}{c}\text { Major axis } \\
\text { current } \\
\mathrm{cm} / \mathrm{s}\end{array}$ & $\begin{array}{c}\text { Minor axis } \\
\text { current }\end{array}$ & Inclination & Phase \\
\hline $\mathrm{cm} / \mathrm{s}$ & degrees & degrees \\
\hline A1 & 3.1 & 0.2 & -7 & 102 \\
\hline A2 & 1.5 & 0.1 & -23 & 73 \\
\hline A3 & 2.5 & 0.3 & 23 & 229 \\
\hline A4 & 2.5 & 0.4 & 12 & 246 \\
\hline A5 & 5.3 & 0.4 & 14 & 203 \\
\hline A6 & 6.4 & 1.3 & 19 & 176 \\
\hline A7 & 10.1 & 1.0 & 10 & 186 \\
\hline A8 & 5.7 & 1.5 & -6 & 141 \\
\hline A9 & 7.5 & 1.8 & 3 & 158 \\
\hline AA & 5.5 & 0.5 & -24 & 91 \\
\hline AB & 5.8 & 0.5 & -16 & 100 \\
\hline AC & 3.8 & 0.3 & -51 & 83 \\
\hline AD & 4.7 & 0.4 & -39 & 74 \\
\hline
\end{tabular}

$\mathbf{S}_{2}$

\begin{tabular}{|c|c|c|c|c||}
\hline \hline Station & $\begin{array}{c}\text { Major axis } \\
\text { current }\end{array}$ & $\begin{array}{c}\text { Minor axis } \\
\text { current }\end{array}$ & Inclination & Phase \\
\hline & $\mathrm{cm} / \mathrm{s}$ & $\mathrm{cm} / \mathrm{s}$ & degrees & degrees \\
\hline \hline A1 & 1.4 & 0.2 & 2 & 134 \\
\hline A2 & 1.5 & 0.1 & -9 & 109 \\
\hline A3 & 0.8 & 0.1 & 39 & 239 \\
\hline A4 & 0.7 & 0.2 & 43 & 257 \\
\hline A5 & 2.3 & 0.2 & 19 & 227 \\
\hline A6 & 2.9 & 0.6 & 23 & 205 \\
\hline A7 & 4.9 & 0.6 & 10 & 177 \\
\hline A8 & 2.2 & 0.5 & -12 & 188 \\
\hline A9 & 3.3 & 0.9 & -26 & 111 \\
\hline AA & 2.4 & 0.8 & -7 & 121 \\
\hline AB & 2.8 & 0.3 & -49 & 97 \\
\hline AC & 1.9 & 0.3 & -29 & 92 \\
\hline AD & 2.1 & 0.0 & & \\
\hline
\end{tabular}

The spatial structures in the modeled and measured barotropic $\mathrm{M}_{2}$ semidiurnal tidal currents over the northwestern portion of the San Pedro shelf (sites AA-AD) were comparable in that both tidal-current fields had amplitudes near $5 \mathrm{~cm} / \mathrm{s}$ and fairly narrow current ellipses (table $7 B$ and fig. 11). In the transition region between the San Pedro to the Palos Verdes shelves and over the Palos Verdes shelf itself, the modeled and measured semidiurnal tidal-current characteristics diverged. The measured tidal-current amplitudes increased in the transition region (sites A6, A7, and A9), and tidal-ellipse orientations were more aligned along the isobaths. The modeled tidal-current amplitudes were about the same as found over the San Pedro shelf; ellipse orientations are more cross-shelf. As one moves onto the Palos Verdes shelf, the measured tidal-current amplitudes weaken until they reach a minimum of $1.5 \mathrm{~cm} / \mathrm{s}$ at site A2, the site located on the narrowest portion of the Palos Verdes shelf. The weakest modeled tidal-current amplitudes were found at sites downcoast of site A2 on a wider portion of the shelf (sites A4 and A5). The tidal-current ellipses in both fields were aligned approximately along the isobaths in this region. 
Table 6A. Ratios of barotropic tidal sea level fluctuations.

[Tidal frequencies are labeled $\mathrm{O}_{1}$ and $\mathrm{K}_{1}$ (diurnal) and $\mathrm{M}_{2}$ and $\mathrm{S}_{2}$ (semidiurnal)]

\begin{tabular}{|l|c|c|c||}
\hline \multicolumn{1}{|c|}{ Station } & $\mathrm{M}_{2} / \mathrm{S}_{2}$ & $\mathrm{~K}_{1} / \mathrm{O}_{1}$ & $\mathrm{M}_{2} / \mathrm{K}_{1}$ \\
\hline B2 pressure & 2.5 & 1.6 & 1.5 \\
\hline B3 pressure & 2.3 & 1.4 & 1.6 \\
\hline B6 pressure & 2.2 & 1.4 & 1.7 \\
\hline $\begin{array}{l}\text { LA harbor } \\
\text { pressure }\end{array}$ & 2.5 & 1.6 & 1.5 \\
\hline
\end{tabular}

Table 6B. Ratios of barotropic tidal current amplitudes.

[Tidal frequencies are labeled $\mathrm{O}_{1}$ and $\mathrm{K}_{1}$ (diurnal) and $\mathrm{M}_{2}$ and $\mathrm{S}_{2}$ (semidiurnal). Current amplitudes are measured along the major axis of the tidal current ellipses]

\begin{tabular}{|c|c|c|c|}
\hline Station & $\mathrm{M}_{2} / \mathrm{S}_{2}$ & $\mathrm{~K}_{1} / \mathrm{O}_{1}$ & $\mathrm{M}_{2} / \mathrm{K}_{1}$ \\
\hline \hline $\mathrm{A} 1$ & 2.2 & 1.6 & 0.8 \\
\hline $\mathrm{A} 2$ & 1.0 & 1.7 & 0.3 \\
\hline $\mathrm{A} 3$ & 3.2 & 1.6 & 0.7 \\
\hline $\mathrm{A} 4$ & 3.5 & 1.7 & 0.5 \\
\hline $\mathrm{A} 5$ & 2.4 & 1.6 & 1.4 \\
\hline $\mathrm{A} 6$ & 2.2 & 1.6 & 2.0 \\
\hline $\mathrm{A} 7$ & 2.1 & 1.7 & 2.4 \\
\hline $\mathrm{A} 8$ & 2.6 & 2.0 & 2.5 \\
\hline $\mathrm{A} 9$ & 2.3 & 1.6 & 2.8 \\
\hline $\mathrm{A} A$ & 2.3 & 1.4 & 1.9 \\
\hline $\mathrm{AB}$ & 2.1 & 1.4 & 2.4 \\
\hline $\mathrm{AC}$ & 2.0 & 1.6 & 2.0 \\
\hline $\mathrm{AD}$ & 2.3 & 1.4 & 2.2 \\
\hline \hline
\end{tabular}

\section{Baroclinic Currents with Periods Near Semidiur- nal Tidal Frequencies}

The fact that the amplitudes of the barotropic semidiurnal tidal currents appeared to change by 20 percent to more than 100 percent when records were only 3 months long, instead of more than a year, suggests that currents associated with semidiurnal internal tides and other coastal ocean processes that have an approximate semidiurnal tidal frequency interact with and cause an apparent increase (or decrease) in estimated barotropic tidal-current amplitudes. In order for these processes to effectively change barotropic tidal-current amplitudes, baroclinic currents must not only be present over the Palos Verdes shelf, but they must (1) have a nonzero, depthaveraged current amplitude, (2) a somewhat stable phase over periods of several months, and (3) an orientation partially aligned with the barotropic tidal current ellipse.

To more easily examine the characteristics of the baroclinic processes at sites in the primary array, current features that were clearly not an internal tide, internal bore, or other baroclinic event with an approximate tidal periodicity were removed from each current record. First, individual current records in each 3-m bin at a site were high-pass-filtered, effectively removing the local mean and local subtidal currents from that record. The principal barotropic diurnal and semidiurnal tidal currents $\left(\mathrm{O}_{1}, \mathrm{~K}_{1}, \mathrm{M}_{2}\right.$, and $\left.\mathrm{S}_{2}\right)$ were then subtracted from each high-pass-filtered current record. For convenience, these records will be called baroclinic current records. They contain vertically sheared current fluctuations from tidal and many other high-frequency coastal ocean processes.

\section{Linear Internal Tidal Current Fluctuations}

A complex demodulation of the baroclinic current record at the semidiurnal frequency shows that energetic, semidiurnal baroclinic currents are present over the Palos Verdes shelf, and, as expected, have amplitudes with considerable vertical structure that varies in time and location both along and across the shelf (fig. 12A). At locations near the shelf break, the 


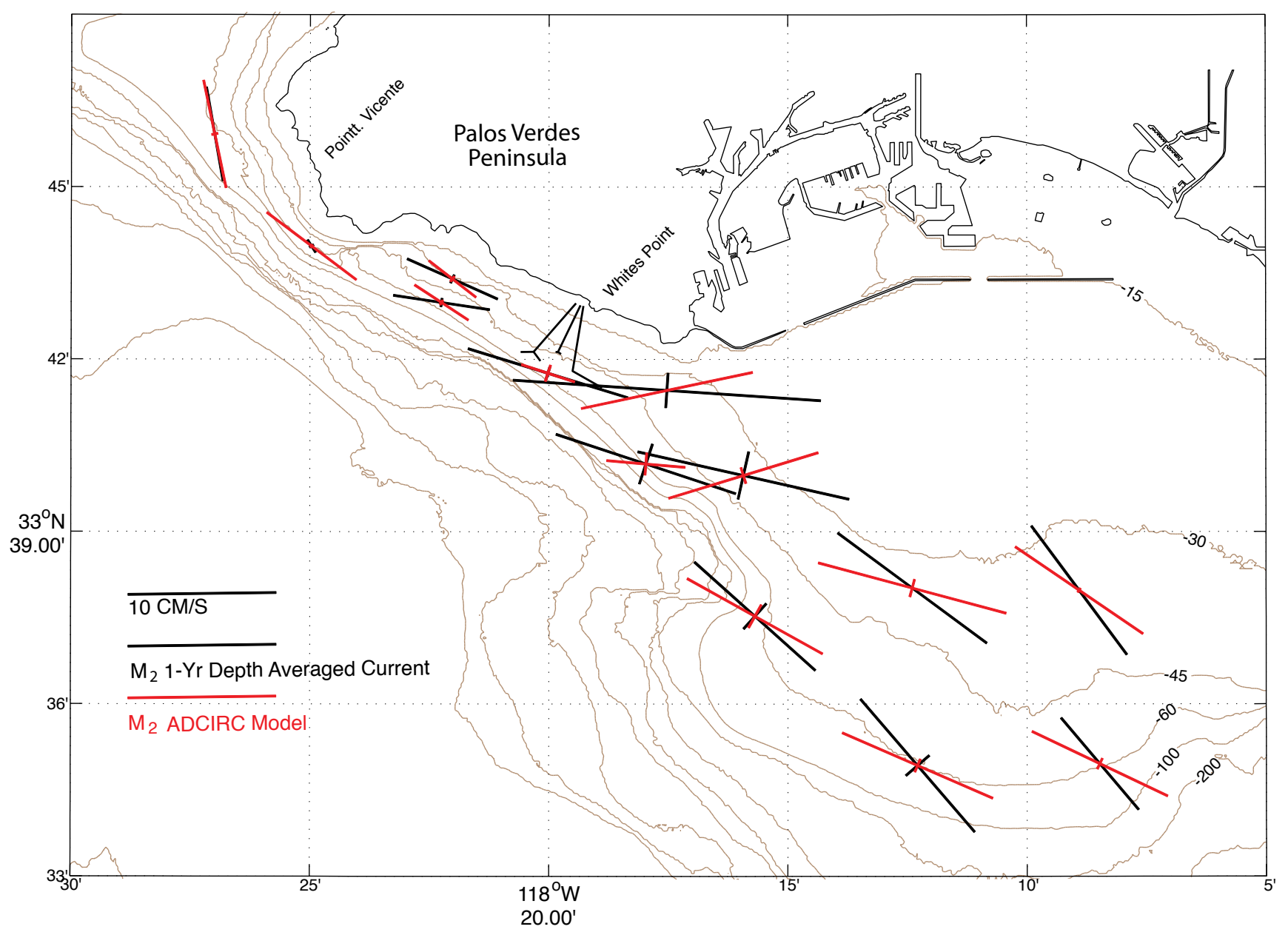

Figure 11. Measured and modeled $M_{2}$ tidal-current amplitudes and inclination angles of the major axes of the $M_{2}$ tidal-current ellipse off the Palos Verdes shelf. The Advanced Circulation (ADCIRC) depth-averaged tidal model for the entire Pacific coast was used to obtain the predicted characteristics of the barotropic tides in this region (Spargo and others, 2004).

strongest semidiurnal current fluctuations tended to be found within $20 \mathrm{~m}$ of the sea surface (figs. $12 B$ and $C$ ). Amplitudes weakened in the middle of the water column, then increased toward the seabed. A similar sheared vertical structure was found in the baroclinic semidiurnal currents along the $35-\mathrm{m}$ isobath, except that the currents near the bed were nearly as strong as the near-surface currents.

The cross-shelf pair of stations located southeast of the outfall, sites A6 and A7, had the largest baroclinic semidiurnal tidal currents (fig. 12A). This station pair also had the largest barotropic semidiurnal tidal currents (table 5). The baroclinic semidiurnal tidal currents were much smaller at the station pair northwest of the outfall, sites A3 and A4, again similar to the barotropic tidal current pattern. The baroclinic current fluctuations had relatively short along-shelf length scales. When energetic fluctuations were found at the shelf break at site A6, weaker fluctuations were often, but not always, found at the companion station upcoast of the outfall (site A3) (fig. 12A).
At both station pairs, if semidiurnal baroclinic current fluctuations were observed at the shelf break, they were also found at the paired site inshore (figs. $12 B$ and $C$ ). This suggests that these baroclinic fluctuations propagated shoreward. As they propagated, the energy tended to concentrate in the shallower waters. Internal tidal amplitudes along the $35-\mathrm{m}$ isobath were larger than amplitudes at the companion shelf-break stations. This increase in baroclinic tidal energy was especially noticeable in current fluctuations near the seabed.

There is no particular temporal pattern in the occurrence of packets of the larger semidiurnal baroclinic currents. Sets of relatively strong internal tidal-period currents occurred for a few weeks in all seasons. There was no hint of the spring/ neap cycle typically found in the semidiurnal barotropic tidal currents in these baroclinic fluctuations.

The duration of individual packets of energetic semidiurnal baroclinic current fluctuations was too short to allow for either a stable characterization of their vertical structure or a 
Table 7A. Amplitude of measured and predicted sea-level fluctuations in the Advanced Circulation (ADCIRC) depth-averaged tidal model for the $\mathrm{M}_{2}$ tides customized for the local topography in the region.

[Tidal frequencies are labeled $\mathrm{M}_{2}$ (semidiurnal). The predicted amplitudes are given for the station pair surrounding the measured amplitude. There was no significant phase change within either the measured (table 4) or predicted semidiurnal sea-level fluctuations]

\begin{tabular}{|c|c|c|c|c|c|}
\hline Station & $\begin{array}{c}\text { Measured } \\
\text { amplitude }\end{array}$ & Station & $\begin{array}{c}\text { Predicted } \\
\text { amplitude }\end{array}$ & Station & $\begin{array}{c}\text { Predicted } \\
\text { amplitude }\end{array}$ \\
\hline & $\mathrm{cm}$ & & $\mathrm{cm}$ & & $\mathrm{cm}$ \\
\hline B2 & 50.7 & $\mathrm{~A} 2$ & 52.1 & $\mathrm{~A} 3$ & 52.1 \\
\hline B3 & 50.7 & $\mathrm{~A} 3$ & 52.1 & A5 & 52.1 \\
\hline B6 & 51.2 & A5 & 52.1 & A6 & 52.2 \\
\hline
\end{tabular}

Table 7B. Characteristics of the measured (Table 5) and modeled barotropic $\mathrm{M}_{2}$ tidal currents over the Palos Verdes and northern San Pedro shelves.

[Tidal frequencies are labeled $\mathrm{M}_{2}$ (semidiurnal). The barotropic currents were modeled using the Advanced Circulation (ADCIRC) depth-averaged tidal model. The inclination angles are counterclockwise from the local along-shelf orientation. When the difference between measured and modeled tidal currents are larger than $1 \mathrm{~cm} / \mathrm{s}$, station names are in bold]

\begin{tabular}{|c|c|c|c|c|c|c|}
\hline & $\begin{array}{c}\text { Measured } \\
\mathrm{M}_{2} \\
\text { currents }\end{array}$ & & & $\begin{array}{c}\text { Modeled } \\
\mathrm{M}_{2} \\
\text { currents }\end{array}$ & & \\
\hline Station & $\begin{array}{c}\text { Major axis } \\
\text { current }\end{array}$ & Eccentricity & Inclination & $\begin{array}{c}\text { Major axis } \\
\text { current }\end{array}$ & Eccentricity & Inclination \\
\hline & $\mathrm{cm}$ & & degrees & $\mathrm{cm}$ & & degrees \\
\hline$\overline{\mathrm{A} 1}$ & 3.1 & 0.06 & -7 & 3.7 & 0.06 & 55 \\
\hline A2 & 1.5 & 0.07 & -23 & 3.8 & 0.03 & -17 \\
\hline A3 & 2.5 & 0.12 & 23 & 2.2 & 0.08 & -31 \\
\hline A4 & 2.5 & 0.16 & 12 & 2.0 & 0.11 & -21 \\
\hline A5 & 5.3 & 0.08 & 14 & 1.9 & 0.31 & -44 \\
\hline A6 & 6.4 & 0.20 & 19 & 2.7 & 0.29 & -53 \\
\hline A7 & 10.1 & 0.10 & 10 & 5.9 & 0.01 & 25 \\
\hline A8 & 5.7 & 0.26 & -6 & 5.3 & 0.17 & -23 \\
\hline A9 & 7.5 & 0.24 & 3 & 5.2 & 0.10 & 39 \\
\hline AA & 5.5 & 0.11 & -24 & 5.5 & 0.09 & -41 \\
\hline $\mathrm{AB}$ & 5.8 & 0.09 & -16 & 6.6 & 0.09 & -53 \\
\hline $\mathbf{A C}$ & 3.8 & 0.09 & -51 & 5.0 & 0.08 & -62 \\
\hline $\mathrm{AD}$ & 4.7 & 0.09 & -39 & 5.2 & 0.03 & -38 \\
\hline
\end{tabular}

separate analysis of the individual constituents in an internal tidal. However, the 2-year internal tidal-current records can be used to calculate the vertical structure of the time-averaged semidiurnal $\mathrm{M}_{2}$ internal tidal currents in the region. This temporally averaged current field will reflect only the most persistent features of the local semidiurnal internal tide and will not necessarily be representative of the individual structures in the energetic packets discussed above.

The near-surface currents in the time-averaged internal tides had amplitudes of $2 \mathrm{~cm} / \mathrm{s}$ at sites near the shelf break, sites $\mathrm{A} 3$ and $\mathrm{A} 6$ (tables $8 A$ and $B$; figs. $13 A$ and $B$ ). Internal tidal-current amplitudes decreased in the middle of the water column, then increased toward the bed. Internal tidal-current fluctuations had a somewhat cross-shelf orientation in the surface waters and an approximate along-shelf orientation near the bed. The phase difference between the surface and nearbed currents was usually only 75 to 100 degrees, not the $180^{\circ}$ phase difference associated with a typical linear internal tide.

The vertical structure of the time-averaged $\mathrm{M}_{2}$ semidiurnal internal tidal currents along the $35-\mathrm{m}$ isobath was more typical (tables $8 C$ and $D$; figs. $13 C$ and $D$ ). The currents had a $180^{\circ}$ phase change between the surface and the bed and were oriented primarily across the shelf. The strongest currents were found at sites southeast of the outfall, similar to the spatial patterns found for other tidal currents in the region.

Even though the time-averaged internal tidal currents near the surface and near the seabed flow opposite to each other, there can still be a non-zero vertical average in the current field for periods of a few months because either the surface or bottom currents are temporarily enhanced or because 


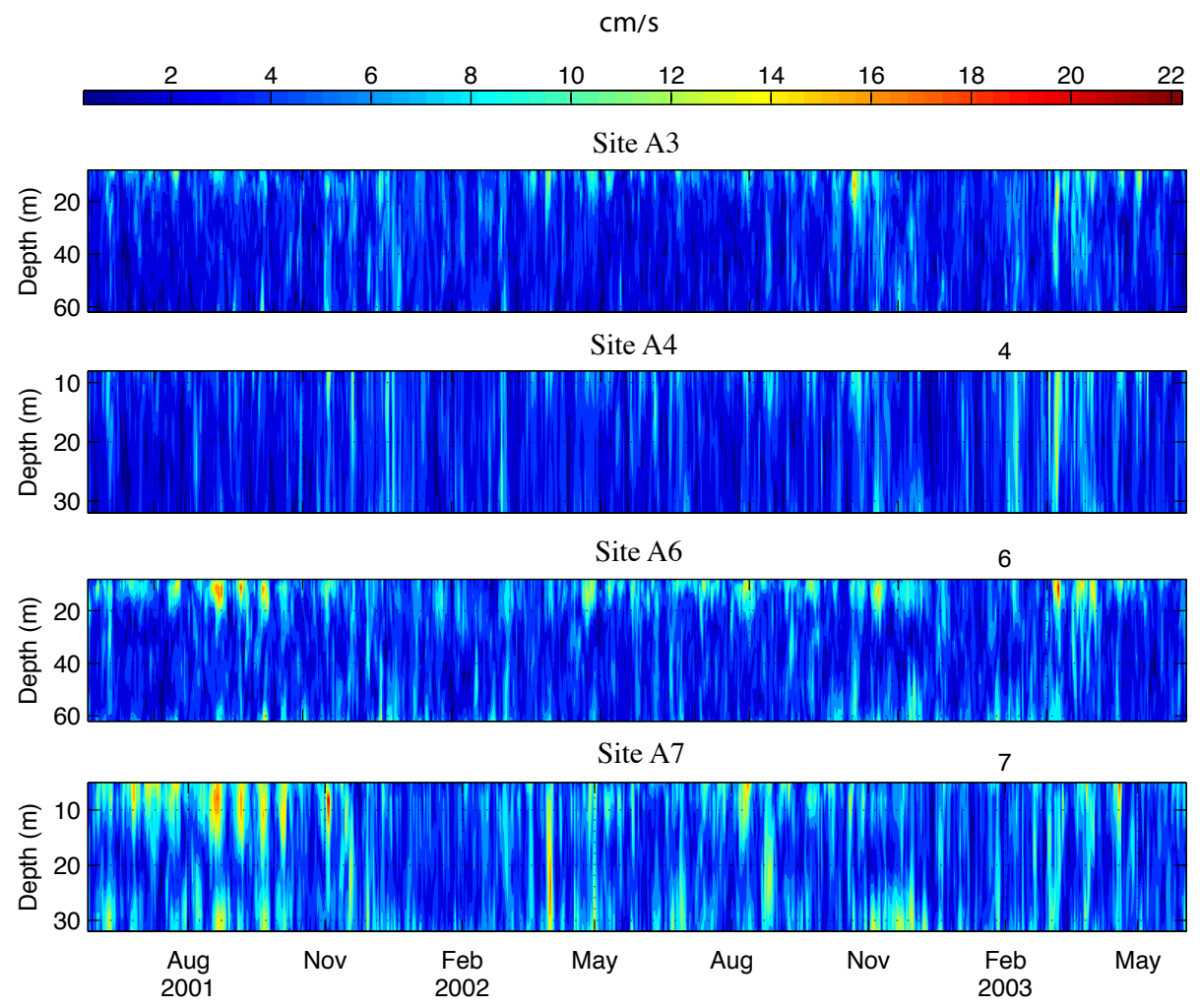

Figure 12A. Complex demodulation of the internal tidal current record depicting the vertical profile of energy in the semidiurnal band at the paired cross-shelf sites $A 3 / A 4$ and A6/A7. The complex demodulation used the $\mathrm{M}_{2}$ frequency and a 4-day window.
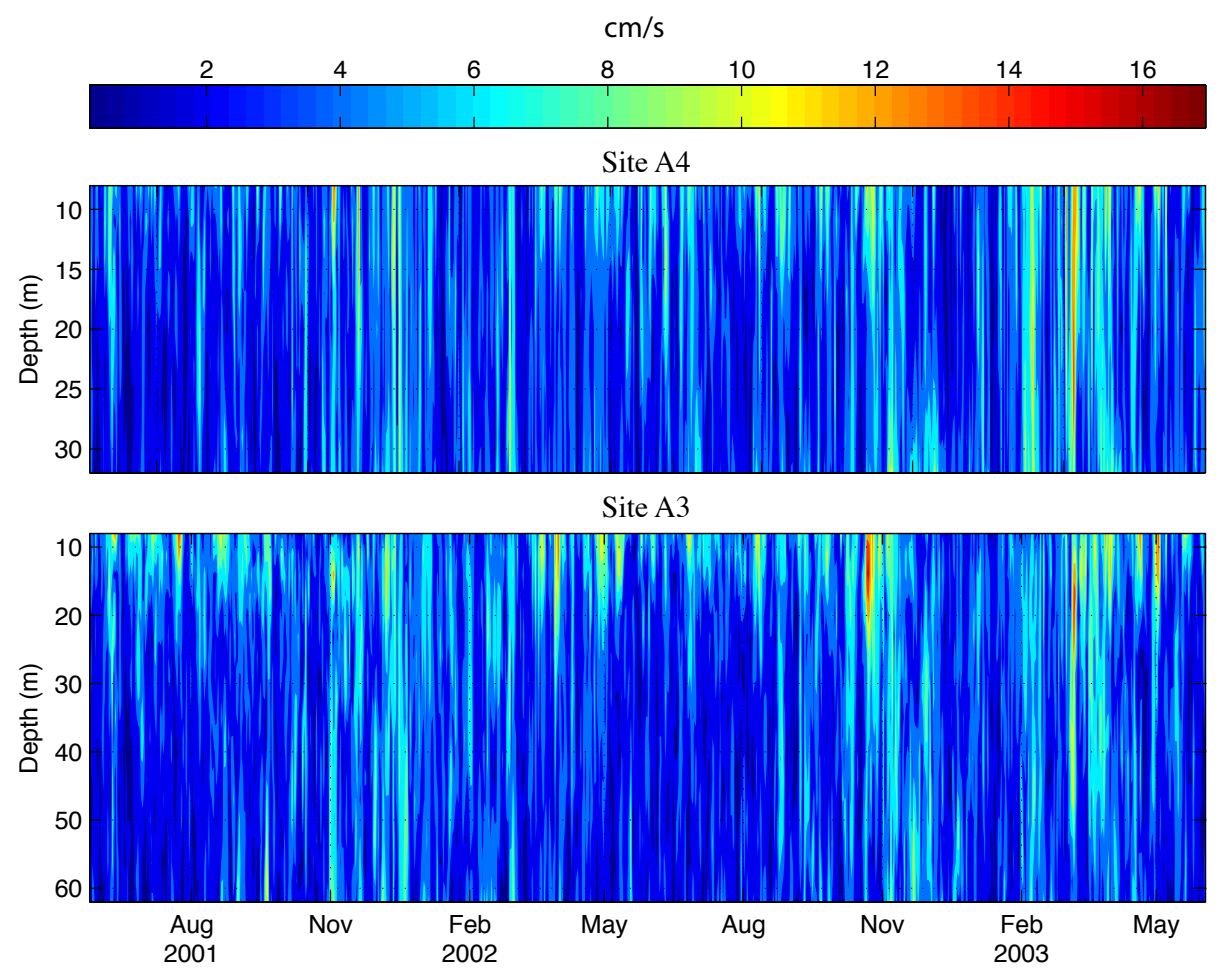

Figure 12B. Complex demodulation of the internal tidal current record depicting the vertical profile of energy in the semidiurnal band along the cross-shelf sites A3/A4. The complex demodulation used the $\mathrm{M}_{2}$ frequency and a 4-day window. Note the scale on the color bar has been changed for clarity. 
Table 8A. Characteristics of the $\mathrm{M}_{2}$ internal tides at site $\mathrm{A} 3$ calculated using 2-year records.

[Tidal frequencies are labeled $\mathrm{M}_{2}$ (semidiurnal). The inclination angle is counterclockwise from the local along-shelf orientation]

\begin{tabular}{|c|c|c|c|c|}
\hline Depth & $\begin{array}{c}\text { Major axis } \\
\text { amplitude } \\
\mathrm{cm} / \mathrm{s}\end{array}$ & $\begin{array}{c}\text { Minor axis } \\
\text { amplitude } \\
\mathrm{cm} / \mathrm{s}\end{array}$ & Inclination & Phase \\
\hline \hline 8 & 2.3 & -0.2 & -67 & degrees \\
\hline 11 & 2.1 & -0.0 & 76 & 70 \\
\hline 14 & 1.9 & -0.0 & 86 & 67 \\
\hline 17 & 1.7 & 0.0 & 87 & 66 \\
\hline 20 & 1.4 & 0.1 & 87 & 62 \\
\hline 23 & 1.2 & 0.2 & 86 & 60 \\
\hline 26 & 0.9 & 0.3 & 89 & 60 \\
\hline 29 & 0.8 & 0.4 & 41 & 58 \\
\hline 32 & 0.6 & 0.5 & 88 & 48 \\
\hline 35 & 0.5 & 0.5 & 26 & 344 \\
\hline 38 & 0.5 & 0.3 & 20 & 336 \\
\hline 41 & 0.5 & 0.3 & 18 & 335 \\
\hline 44 & 0.5 & 0.2 & 16 & 329 \\
\hline 47 & 0.4 & 0.2 & 6 & 317 \\
\hline 50 & 0.2 & 0.0 & -1 & 310 \\
\hline 53 & 0.1 & -0.0 & -25 & 298 \\
\hline 56 & 0.2 & 0.1 & 33 & 166 \\
\hline 59 & 0.5 & 0.2 & 11 & 146 \\
\hline 62 & 0.8 & 0.3 & -4 & 129 \\
\hline
\end{tabular}

Table 8B. Characteristics of the $M_{2}$ internal tides at site $A 6$ calculated using 2-year records.

[Tidal frequencies are labeled $\mathrm{M}_{2}$ (semidiurnal). The inclination angle is counterclockwise from the local along-shelf orientation]

\begin{tabular}{|c|c|c|c|c|}
\hline Depth & $\begin{array}{c}\text { Major axis } \\
\text { amplitude } \\
\mathrm{cm} / \mathrm{s}\end{array}$ & $\begin{array}{c}\text { Minor axis } \\
\text { amplitude } \\
\mathrm{cm} / \mathrm{s}\end{array}$ & Inclination & Phase \\
\hline & & & & degrees \\
\hline 8 & 2.0 & 1.0 & 89 & 157 \\
\hline 11 & 2.4 & 0.9 & -52 & 182 \\
\hline 14 & 2.2 & 0.8 & -50 & 182 \\
\hline 17 & 1.8 & 0.8 & -51 & 180 \\
\hline 20 & 1.3 & 0.9 & -47 & 184 \\
\hline 23 & 1.3 & 0.9 & 16 & 249 \\
\hline 26 & 1.2 & 0.6 & 31 & 264 \\
\hline 29 & 1.2 & 0.3 & 37 & 269 \\
\hline 32 & 1.2 & 0.1 & 41 & 269 \\
\hline 35 & 1.2 & -0.1 & 43 & 266 \\
\hline 38 & 1.1 & -0.1 & 41 & 262 \\
\hline 41 & 1.1 & -0.1 & 39 & 258 \\
\hline 44 & 1.0 & -0.1 & 34 & 255 \\
\hline 47 & 0.8 & 0.0 & 25 & 250 \\
\hline 50 & 0.5 & 0.1 & 3 & 238 \\
\hline 53 & 0.3 & -0.1 & -46 & 212 \\
\hline 56 & 0.6 & -0.2 & 47 & 77 \\
\hline 59 & 1.2 & 0.0 & 28 & 73 \\
\hline 62 & 1.8 & 0.3 & 15 & 65 \\
\hline & & & & \\
\hline
\end{tabular}
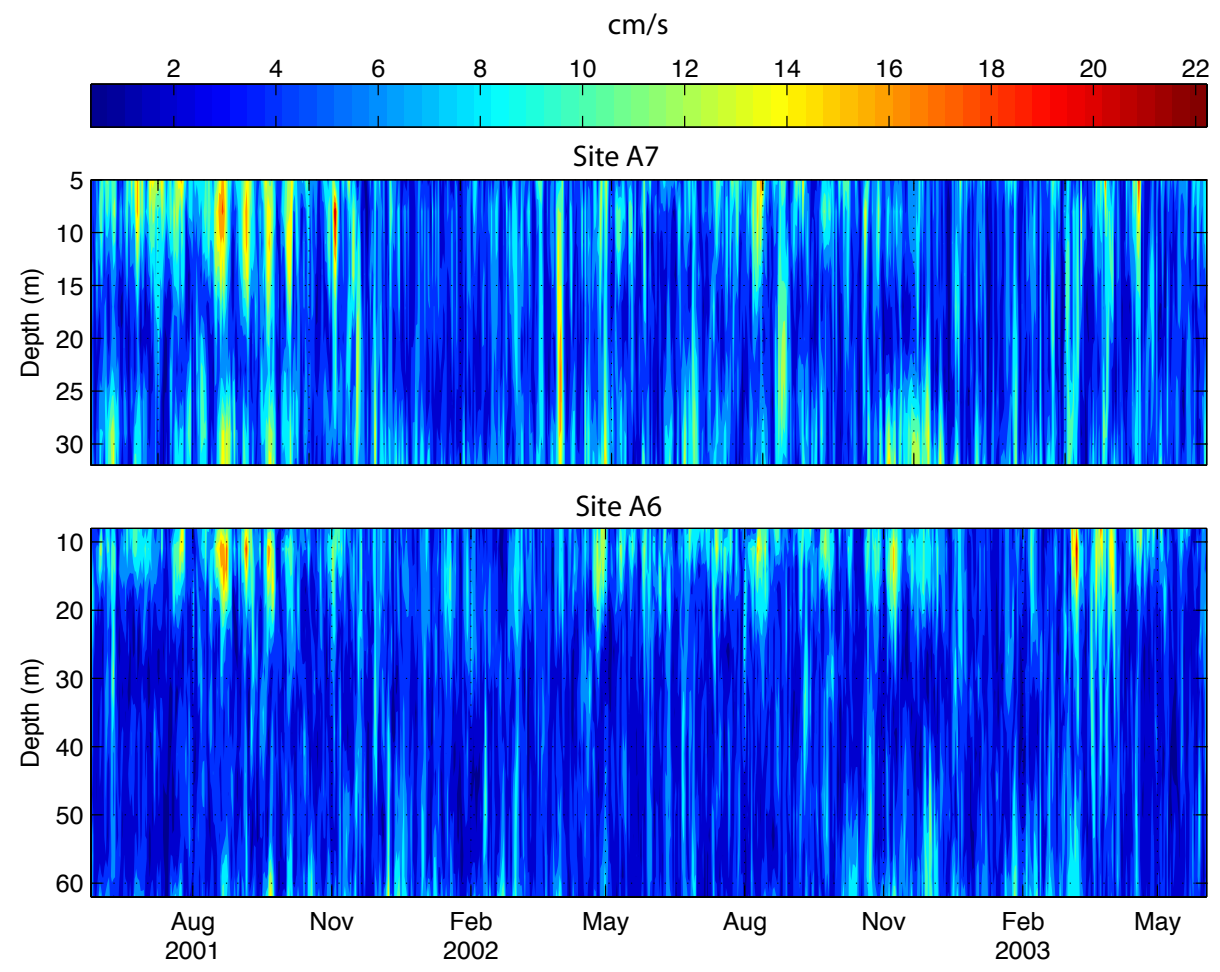

Figure 12C. Complex demodulation of the internal tidal current record depicting the vertical profile of energy in the semidiurnal band along the cross-shelf sites A6/A7. The complex demodulation used the $\mathrm{M}_{2}$ frequency and a 4-day window. Note the scale on the color bar has been changed for clarity. 
Table 8C. Characteristics of the $\mathrm{M}_{2}$ internal tides at site $\mathrm{A} 4$ calculated using 2-year records.

[Tidal frequencies are labeled $\mathrm{M}_{2}$ (semidiurnal). The inclination angle is counterclockwise from the local along-shelf orientation]

\begin{tabular}{|c|c|c|c|c||}
\hline \hline Depth & $\begin{array}{c}\text { Major axis } \\
\text { amplitude }\end{array}$ & $\begin{array}{c}\text { Minor axis } \\
\text { amplitude }\end{array}$ & Inclination & Phase \\
\hline $\mathrm{cm} / \mathrm{s}$ & $\mathrm{cm} / \mathrm{s}$ & degrees & degrees \\
\hline \hline 8 & 1.4 & -0.4 & 73 & 88 \\
\hline 11 & 1.1 & -0.2 & 81 & 85 \\
\hline 14 & 0.7 & 0.0 & 86 & 82 \\
\hline 17 & 0.3 & 0.1 & -84 & 84 \\
\hline 20 & 0.2 & 0.0 & -10 & 338 \\
\hline 23 & 0.2 & -0.1 & 68 & 261 \\
\hline 26 & 0.4 & -0.1 & 74 & 261 \\
\hline 29 & 0.6 & 0.1 & 83 & 262 \\
\hline 32 & 0.9 & 0.2 & -80 & 273 \\
\hline
\end{tabular}

Table 8D. Characteristics of the $\mathrm{M}_{2}$ internal tides at site $\mathrm{A} 7 \mathrm{calcu}$ lated using 2-year records.

[Tidal frequencies are labeled $\mathrm{M}_{2}$ (semidiurnal). The inclination angle is counterclockwise from the local along-shelf orientation]

\begin{tabular}{|c|c|c|c|c||}
\hline Depth & $\begin{array}{c}\text { Major } \\
\text { amplitude } \\
\mathrm{cm} / \mathrm{s}\end{array}$ & $\begin{array}{c}\text { Minor } \\
\text { amplitude }\end{array}$ & Inclination & Phase \\
\hline $\mathrm{cm} / \mathrm{s}$ & degrees & degrees \\
\hline 8 & 2.8 & -0.3 & 72 & 24 \\
\hline 11 & 2.6 & -0.4 & 70 & 26 \\
\hline 14 & 2.1 & -0.2 & 69 & 29 \\
\hline 17 & 1.3 & 0.1 & 73 & 38 \\
\hline 20 & 0.6 & 0.1 & -75 & 81 \\
\hline 23 & 0.6 & -0.5 & 61 & 187 \\
\hline 26 & 1.5 & -0.3 & 56 & 208 \\
\hline 29 & 2.1 & -0.1 & 67 & 215 \\
\hline 32 & 2.5 & 0.3 & -85 & 228 \\
\hline
\end{tabular}
Phase (degrees)

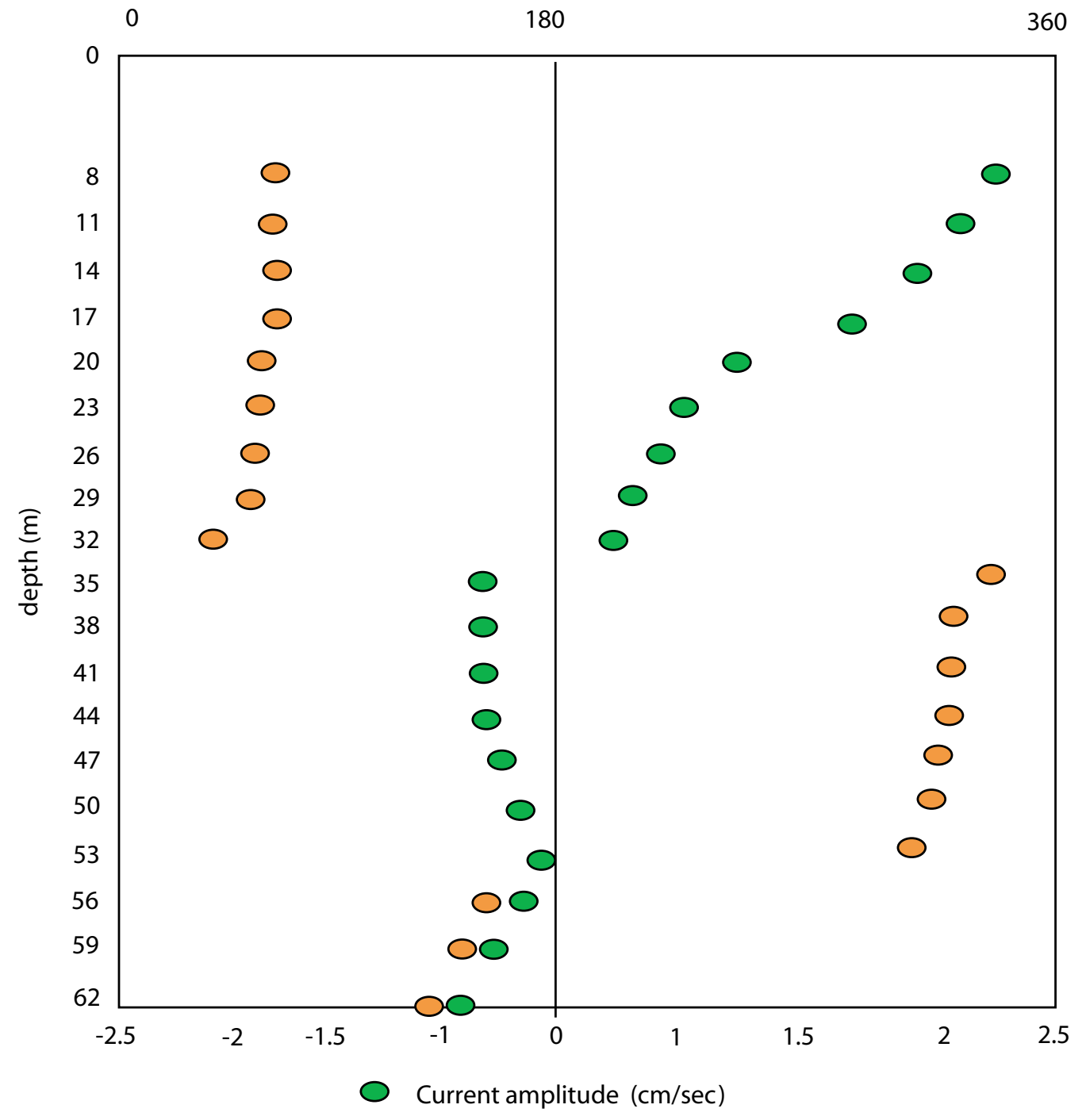

Figure 13A. Vertical profile of the amplitude and phase of the $M_{2}$ internal tidal current for the 2-year record at site $A 3$ (see table $8 A$ ). Negative amplitude indicates that current is directed $180^{\circ}$ away from positive values. 
the relative orientation of the surface and/or bottom currents rotate with time. These temporary asymmetries or rotations cause an apparent barotropic component in the internal tidal current field in short sections of record. The apparent amplitude of a barotropic tide in baroclinic records on the Palos Verdes shelf that are 3 months long ranges from 0.4 to 2.8 $\mathrm{cm} / \mathrm{s}$ (table 9). These amplitudes are large enough to account for much of the variability in barotropic tidal amplitudes calculated from the sequential three-month barotropic record segments (table 3 ). Hence, the observed variations in the measured barotropic tidal current over time are, in part, caused by interactions between the barotropic and the time-varying baroclinic internal tidal-current fields.

\section{Nonlinear Internal Tidal/Internal Bore Events}

Many events in the baroclinic current records had much stronger velocities than found in the time-averaged linear internal tides discussed above. The largest events lasted several hours and occurred every 24 hours (figs. $14 A$ and $B$ ). A series of events tended to cluster for periods of 7 to 10 days. The events then disappeared for a week or more. Less energetic events with similar current structures occurred in the 12-hour intervals that lay between the larger 24-hour events. The series of events depicted in figures $14 A$ and $B$ appeared first at the outer shelf site $\mathrm{A} 6$, then one to two hours later at the inner shelf site. The phase speed, $1-3 \mathrm{~km} / \mathrm{h}$, is consistent with rough

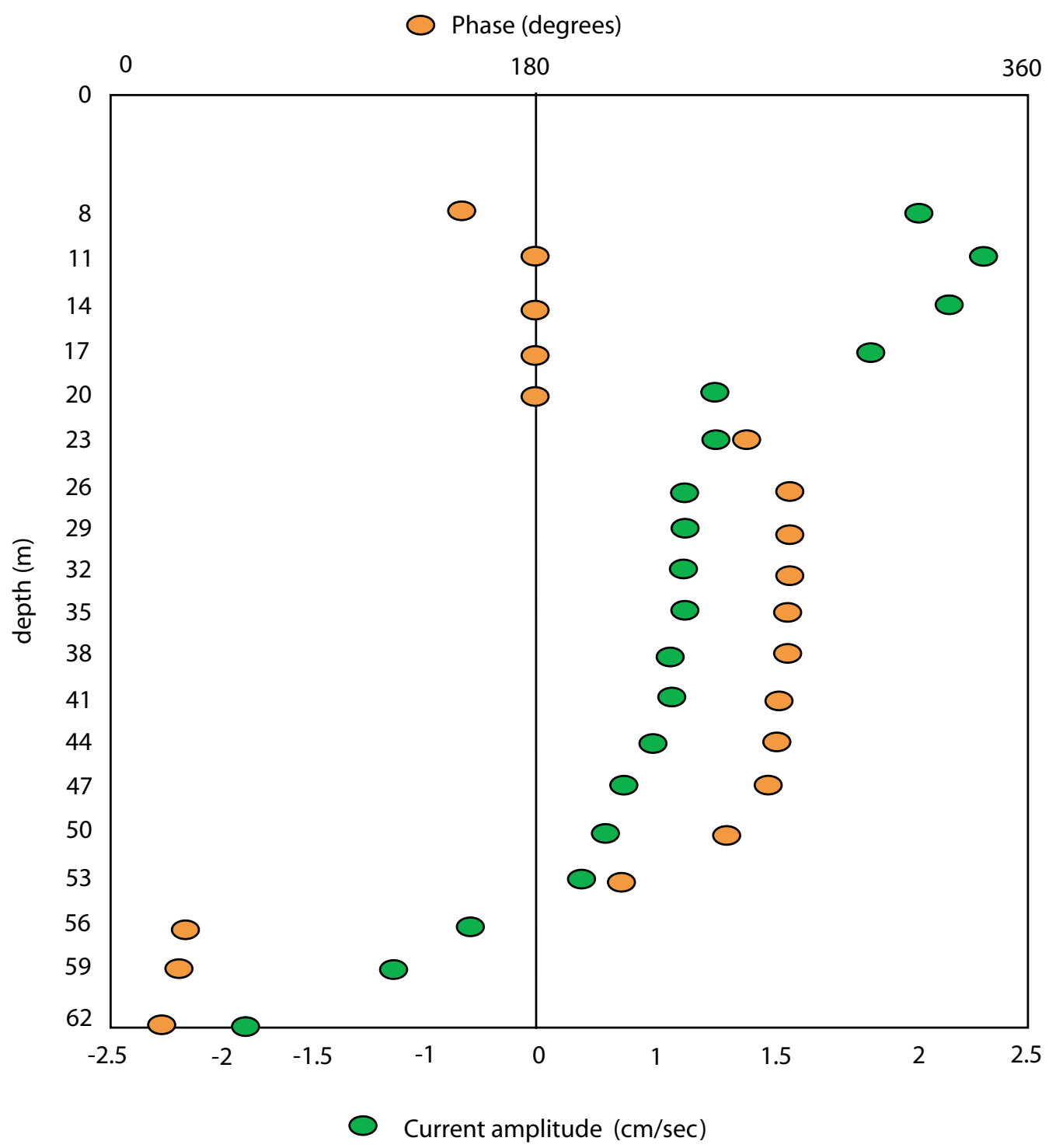

Figure 13B. Vertical profile of the amplitude and phase of the $\mathrm{M}_{2}$ internal tidal current for the 2-year record at site $A 6$ (see table $8 B$ ). Negative amplitude indicates that current is directed $180^{\circ}$ away from positive values. 


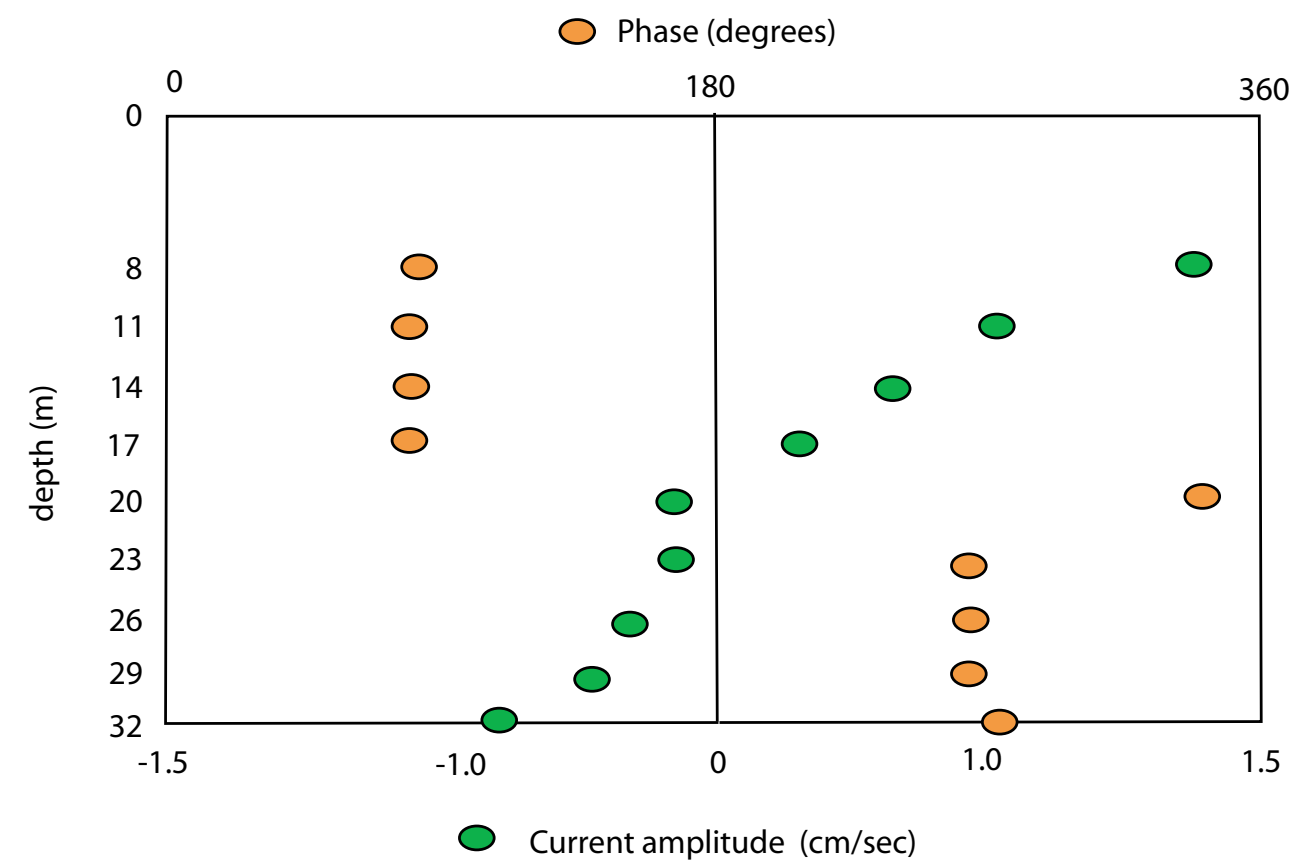

Figure 13C. Vertical profile of the amplitude and phase of the $M_{2}$ internal tidal current for the 2-year record at site $A 4$ (see table $8 \mathrm{C}$ ). Negative amplitude indicates that current is directed $180^{\circ}$ away from positive values.

estimates of the phase speed for relatively long internal waves propagating through a shallow 2-layer coastal ocean.

The near-bed current during the most energetic events was much stronger than the near-surface current (figs. $14 \mathrm{~A}$ and $B$ ). This vertical current structure is not typically found in a linear internal tide. The vertical phase structure in these events was more typical in that the surface currents flowed opposite to those near the bed. When an energetic event passed the mooring site, it tended to draw the warmer surface waters down more than $20 \mathrm{~m}$.

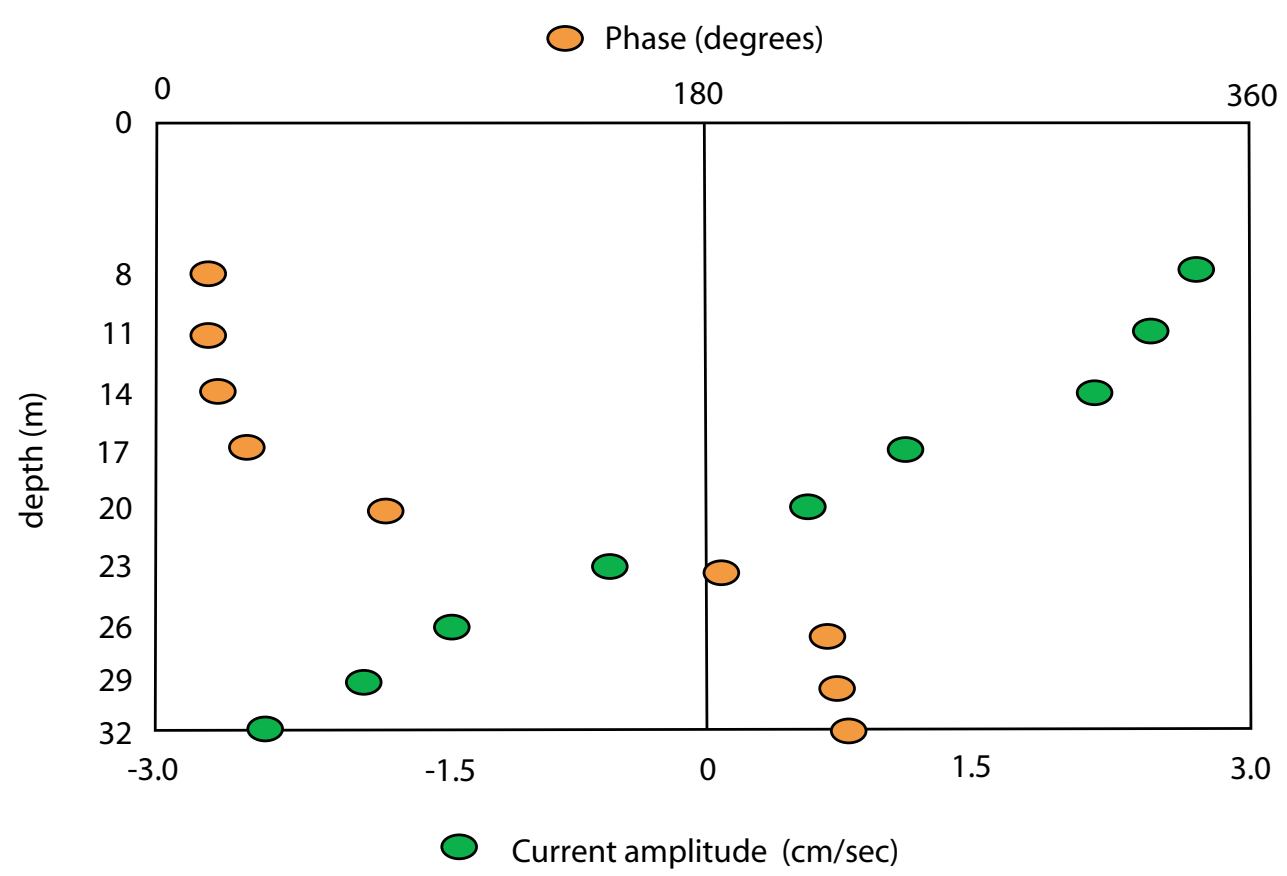

Figure 13D. Vertical profile of the amplitude and phase of the $M_{2}$ internal tidal current for the 2-year record at site $A 7$ (see table $8 D$ ). Negative amplitude indicates that current is directed $180^{\circ}$ away from positive values. 
Table 9. Barotropic (BT) tidal-current amplitudes in the 2-year current record (table 5) and apparent barotropic tides calculated using the baroclinic current records for successive 3-month sections of the record.

\begin{tabular}{|c|c|c|}
\hline Station & BT tidal current & $\begin{array}{c}\text { Range of the apparent } \\
\text { BT in baroclinic record } \\
\text { segments that are } 3 \\
\text { months long }\end{array}$ \\
\cline { 2 - 3 } & $\begin{array}{c}\text { Major axis current } \\
\text { amplitude }\end{array}$ & $\begin{array}{c}\text { Major axis current } \\
\text { amplitude }\end{array}$ \\
\cline { 2 - 3 } & $\mathrm{cm} / \mathrm{s}$ & $\mathrm{cm} / \mathrm{s}$ \\
\hline \hline A3 & 2.5 & 0.8 to 2.0 \\
\hline A4 & 2.5 & 0.4 to 2.8 \\
\hline A6 & 6.4 & 0.4 to 2.3 \\
\hline A7 & 10.1 & 0.4 to 1.9 \\
\hline
\end{tabular}

A more detailed look at the vertical structure of currents in some of these events showed that current speeds were largest just $3 \mathrm{~m}$ above the bed. Near-bed current speeds could reach $40 \mathrm{~cm} / \mathrm{s}$ or more as the center of an event passed the site. These near-bed currents were directed offshore and upcoast for periods of 2 to 4 hours. The oscillations in these near-bed current events were assymetric in that they did not have an equally large downcoast and onshore flow; near-bed onshore current amplitudes tended to be at least 5 to $10 \mathrm{~cm} / \mathrm{s}$ weaker than offshore amplitudes. Current speeds decreased markedly with depth off the seabed, becoming negligible at sites in the lower third to one-half of the water column. Then the currents reversed direction and increased in amplitude toward the sea surface, though near-surface current amplitudes never approached that of the near-bed currents.

In order to better characterize the number, temporal and spatial pattern of internal events with strong near-bottom flows and periods less than 30 hours, currents sampled every 15 minutes in the baroclinic record were divided into three categories:

(1) The average current amplitude in the 3 bins nearest the bed was larger than $20 \mathrm{~cm} / \mathrm{s}$.

(2) Average current amplitude in the 3 bins nearest the bed was larger than $20 \mathrm{~cm} / \mathrm{s}$ and at least $15 \mathrm{~cm} / \mathrm{s}$ larger than the average amplitude in the 3 bins that spanned the middle of the water column. This mid-depth criteria for currents was located at the depth where the individual vertically sheared asymmet-
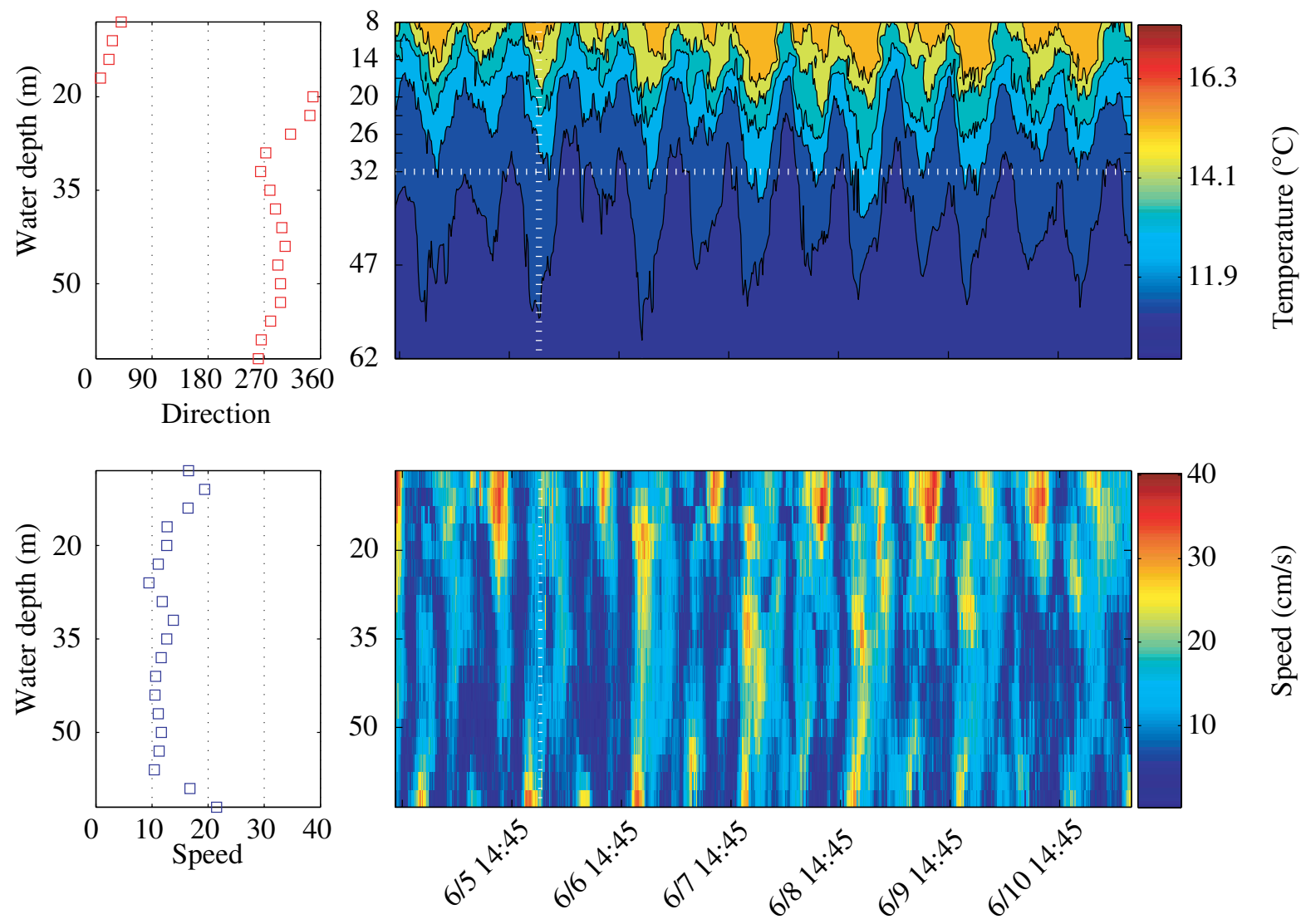

Figure 14A. Observed internal bores in $65 \mathrm{~m}$ of water at site $A 6$ in June 2001. The profiles of current direction and speed at the left of the figure are shown for June 5, 2001, at 20:00 GMT (time indicated by vertical dashed white line in main panels). This is the time that an internal bore event was most obvious at the inshore site A7. Note that these profiles were collected 1 to 2 hours after the event passed the shelf-break site as the strong near-bed currents are found earlier in the record. Note that there are slight changes in thecolor scales between the two fgures. 
ric events discussed above commonly reversed their flow.

(3) All other currents.

Category 1 selects for all current events in the baroclinic record that can potentially resuspend fine sediments. Category 2 is a subset of category 1 in that category 2 events have significant vertical shear in addition to strong bottom currents. Hence, category 2 captures some, but not all, internal events that are potentially characterized as internal tides or bores. If the minimum current in a particular energetic internal bore event occurs either above or below the middle of the water column, then it is classified as a category 1 event. The nearbed currents in category 3 are not energetic and will not be discussed.

The strong near-bed currents in the baroclinic record occurred most often at the sites southeast of both the outfall and the effluent-affected sediment deposit (sites A6-A9) (table 10). These same sites also had the most numerous energetic current events in the complete current record. The paired cross-shelf array south of the outfall (sites A6 and A7) had at least twice as many energetic events in both the basic and baroclinic current record as did the pair of stations over the effluent-affected deposit (sites A3 and A4). A closer examination of the strength of the current events shows that they were typically much stronger at the paired set of stations upcoast of the outfall (fig. 15).

Near-bottom currents at the shelf break were often larger than $40 \mathrm{~cm} / \mathrm{s}$ at the downcoast site A6 and usually less than $40 \mathrm{~cm} / \mathrm{s}$ at the upcoast site A3. Not only did these energetic events tend to propagate across the shelf, but the energy in the events usually increased at the sites in shallower water. The largest near-bottom current speeds were found more often at the inshore station pair. This is the same spatial pattern observed in the semidiurnal surface and internal tidal currents.

The event packets in both categories had fairly short alongshelf length scales; the temporal patterns in the event packets were unrelated even for sites separated by only $12 \mathrm{~km}$ along the shelf (fig. 15). The strongest internal events at the sites southeast of the deposit (A6 and A7) were found in the summer of 2001. The strongest events occurred in the late fall and early winter of 2003 at the sites to the northwest (A3 and A4).
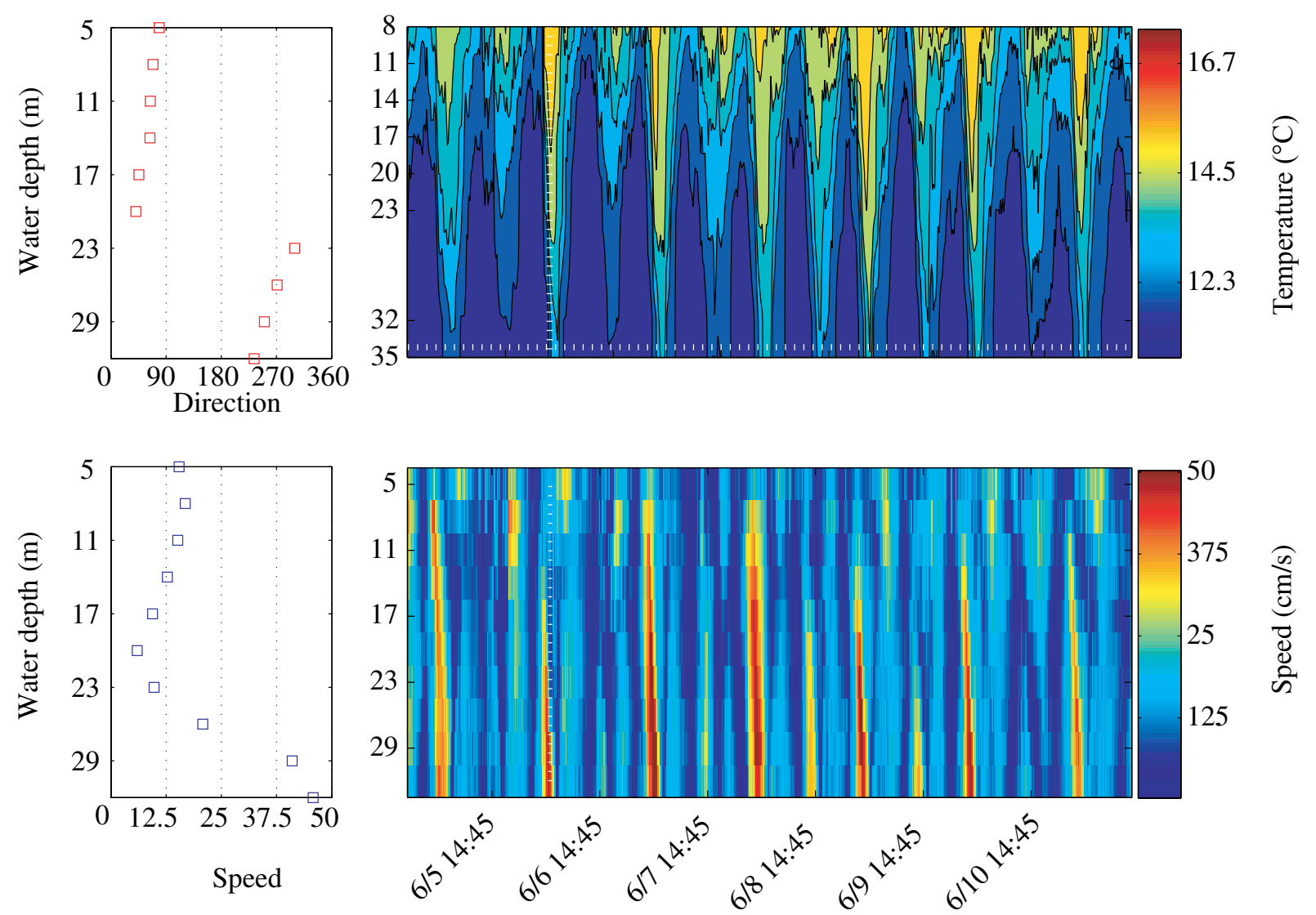

Speed

Figure 14B. Observed internal bores in $35 \mathrm{~m}$ of water at site $\mathrm{A} 7$ in June 2001. The profiles of current direction and speed at the left of the figure are shown for June 5, 2001, at 20:00 GMT (time indicated by vertical dashed white line in main panels). This is the time that the center of an internal bore event passed site 7. 
Table 10. Total number of events in the various current records with speeds greater than $20 \mathrm{~cm} / \mathrm{s}$.

[Record length is 2 years long and the sampling interval is 15 minutes. Each current record is 70,973 points long]

\begin{tabular}{|c|l|l|l|}
\hline Station & Raw current record & \multicolumn{1}{|c|}{$\begin{array}{c}\text { Baroclinic current } \\
\text { record }\end{array}$} & \multicolumn{1}{|c|}{$\begin{array}{c}\text { Raw-baroclinic } \\
\text { current record }\end{array}$} \\
\hline \hline A2 & 3749 & 379 & 1826 \\
\hline A3 & 1576 & 257 & 73 \\
\hline A4 & 2241 & 384 & 246 \\
\hline A5 & 2219 & 234 & 406 \\
\hline A6 & 5403 & 416 & 875 \\
\hline A7 & 10786 & 1566 & 4194 \\
\hline A8 & 5417 & 975 & 642 \\
\hline A9 & 5810 & 523 & 1014 \\
\hline
\end{tabular}
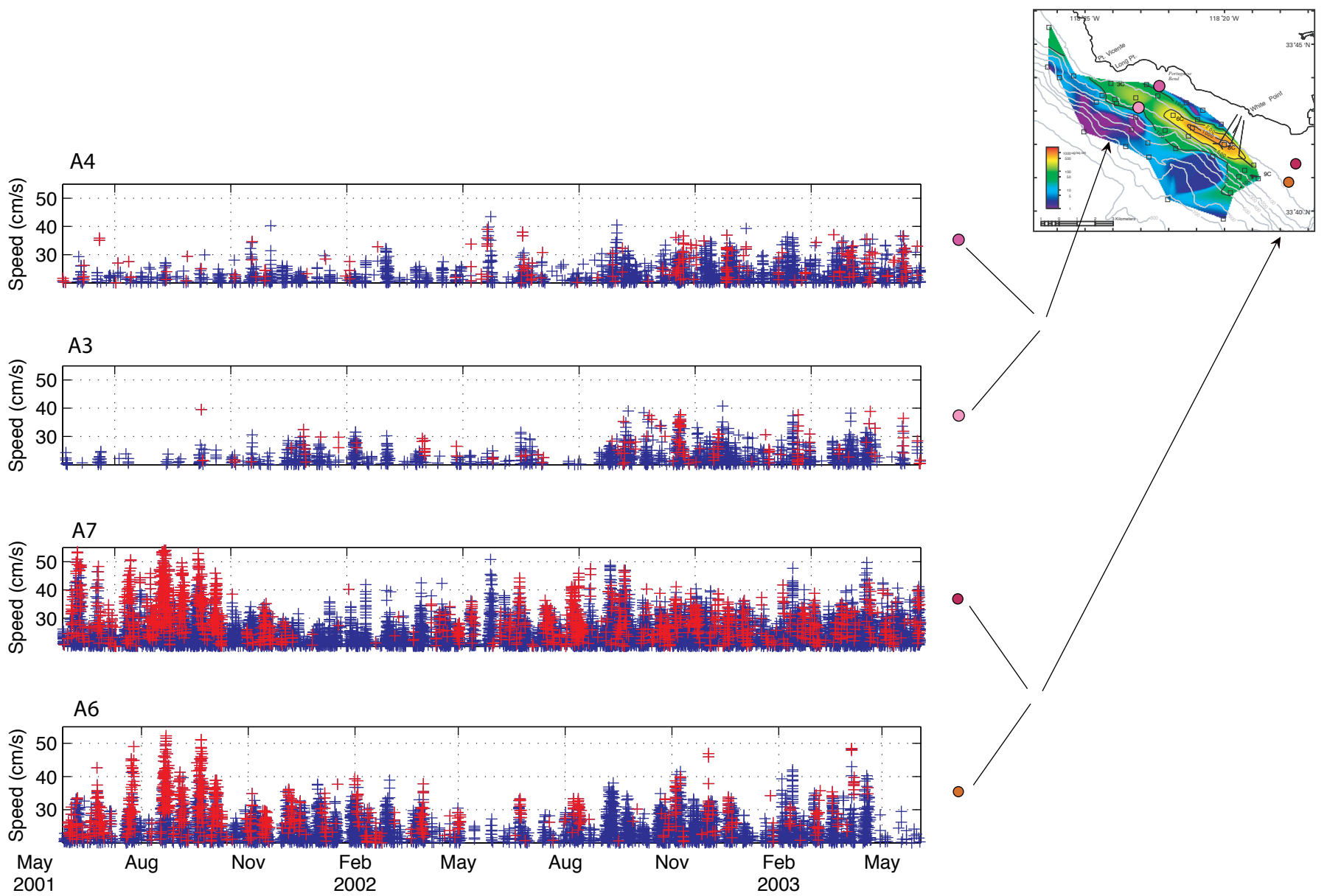

Figure 15. Near-bed currents with speeds greater than $20 \mathrm{~cm} / \mathrm{s}$ in the baroclinic records at two sets of paired cross-shelf sites (A3/A4 and A6/A7) on the Palos Verdes shelf. Baroclinic events with a pronounced vertical structure are red. Baroclinic events with less vertical structure are blue. 
Table 11. The percentages of near-bottom current speeds that are greater than $20 \mathrm{~cm} / \mathrm{s}$ in the 15 -minute records are grouped into two directional bins.

[Bins are defined to be all strong near-bottom currents with (1) directions within 45 degrees of the positive along-shelf orientation (315-45 degrees where 0 degrees is positive along-shelf) and (2) within 45 degrees of off-shelf/positive along-shelf orientation (270-315 degrees where 270 is offshelf). Note that the bin for off-shelf current flow is half the size of the along-shelf bin. This is because the positive alongshelf events tend to be distributed both on the on- and off-shelf sides of the along-shelf direction. The off-shelf events are mainly found only in the positive along-shelf portion of the off-shelf quadrant. The raw baroclinic current record has energetic near-bottom currents because the subtidal flow, not discussed in this paper, is strong over the Palos Verdes and northern San Pedro shelves]

\begin{tabular}{||l|l|l|l|l|l|l||}
\hline Station & $\begin{array}{l}\text { Raw } \\
\text { record }\end{array}$ & $\begin{array}{l}\text { Baroclinic } \\
\text { record }\end{array}$ & $\begin{array}{l}\text { Raw-baroclinic } \\
\text { record }\end{array}$ & \\
\cline { 2 - 7 } & $\begin{array}{l}\text { Positive } \\
\text { along-shelf }\end{array}$ & Off-shelf & $\begin{array}{l}\text { Positive } \\
\text { along-shelf }\end{array}$ & Offshelf & $\begin{array}{l}\text { Positive along- } \\
\text { shelf }\end{array}$ & Off-shelf \\
\hline & $\%$ & $\%$ & $\%$ & $\%$ & $\%$ & $\%$ \\
\hline A2 & $\mathbf{8 5}$ & 2 & $\mathbf{4 7}$ & 5 & $\mathbf{9 9}$ & 0 \\
\hline A3 & $\mathbf{6 1}$ & 22 & 27 & $\mathbf{3 4}$ & $\mathbf{6 7}$ & 0 \\
\hline A4 & $\mathbf{7 2}$ & 11 & 19 & $\mathbf{3 3}$ & $\mathbf{9 8}$ & 0 \\
\hline A5 & $\mathbf{4 1}$ & 30 & 15 & $\mathbf{4 8}$ & $\mathbf{5 5}$ & 4 \\
\hline A6 & 43 & $\mathbf{5 0}$ & 12 & $\mathbf{6 5}$ & $\mathbf{5 6}$ & 44 \\
\hline A7 & $\mathbf{4 9}$ & 14 & 15 & $\mathbf{4 6}$ & $\mathbf{6 5}$ & 8 \\
\hline A8 & $\mathbf{8 2}$ & 4 & $\mathbf{3 6}$ & 3 & $\mathbf{9 9}$ & 1 \\
\hline A9 & $\mathbf{6 4}$ & 13 & 22 & $\mathbf{4 8}$ & $\mathbf{7 9}$ & 2 \\
\hline \hline
\end{tabular}

There was no obvious temporal pattern in the currents in either category or at either site. All categories had clusters of strong near-bed flows that lasted for periods of a few months (fig. 15). These event clusters would then disappear for the following few months. The occurrence of a series of these energetic events did not appear to be associated with the presence of strong barotropic tidal currents in that they did not cluster around the spring/neap tidal cycle.

The oscillations in these strong near-bed currents were very asymmetric. More than 70 percent of those observed at the shelf-break site southeast of the deposit (site A6) flowed offshore and upcoast (fig. 16A). Less than 10 percent of them flowed onshore and downcoast. A similar pattern was seen at the companion site along the $35-\mathrm{m}$ isobath, though the asymmetry was not as marked. Sixty percent of the stronger near-bed currents at site A7 flowed offshore and upcoast. Less than 30 percent flowed onshore and downcoast. At the more quiescent pair of cross-shelf sites located on the deposit, more than 43 percent of the energetic near-bottom currents at the shelf break were directed offshore and upcoast, whereas only 11 percent were directed onshore and downcoast (fig. 16B). Similar asymmetries were seen in the near-bed flows at the companion stations along the $35-\mathrm{m}$ isobath.

It is interesting to note that when one sums up events in adjacent quadrants, the dominant pattern is that energetic nearbottom currents in the two categories have a strong preference for moving suspended material offshore. At the sites near the shelf break, between 69 percent and 90 percent of the events have an offshore component, irrespective of their along-shelf flow direction (figs. $16 A$ and $B$ ). At sites along the $35-\mathrm{m}$ isobath, between 68 percent and 79 percent have an offshore component.

The energetic near-bed currents in the basic current record tend to move suspended material along the shelf toward the northwest (table 11). However, the baroclinic portion of the current field has a strong tendency to transport material suspended near the bed off, as well as along the shelf (table 11; fig. 17). The dominant direction for the energetic nearbed baroclinic currents is predominantly offshore and slightly upcoast. At most sites over the Palos Verdes peninsula, 30 to more than 60 percent of the strong near-bottom baroclinic currents move suspended material predominantly toward the shelf break. This is in contrast to the energetic near-bottom flows in the combined mean, subtidal, and barotropic tidalcurrent fields. They tend to move material suspended near the bed along the shelf; directions are usually within $45^{\circ}$ of the upcoast orientation. This is to be expected, given that the mean, subtidal, and barotropic tidal currents are aligned preferentially along the isobaths.

\section{Discussion}

\section{Barotropic, Baroclinic Tidal Currents, and Inter- nal Bores}

It is well known that the semidiurnal barotropic tide off California propagates toward the northwest primarily 

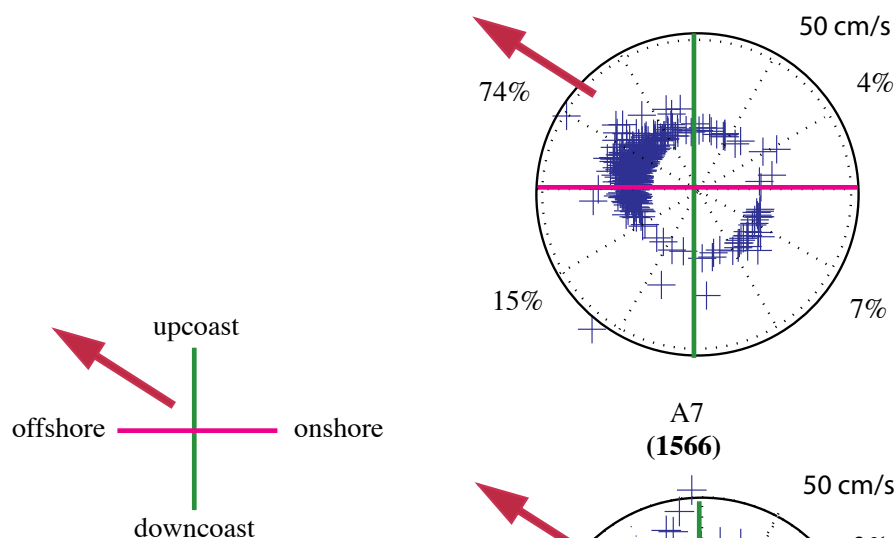

A7

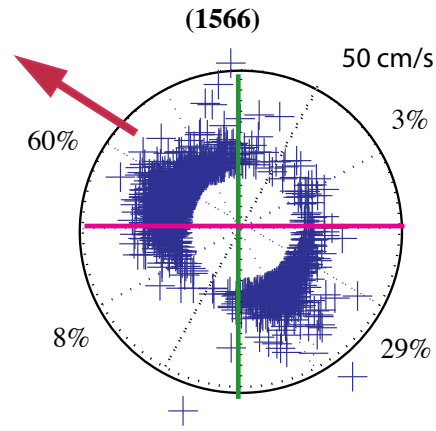

Category 1 events
A6

(126)

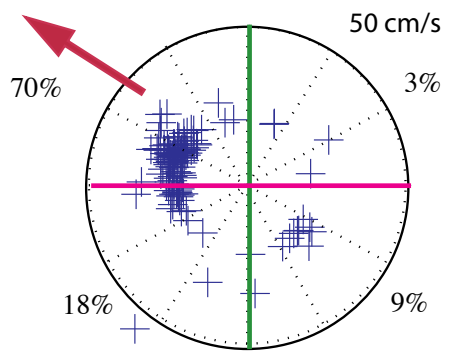

A7

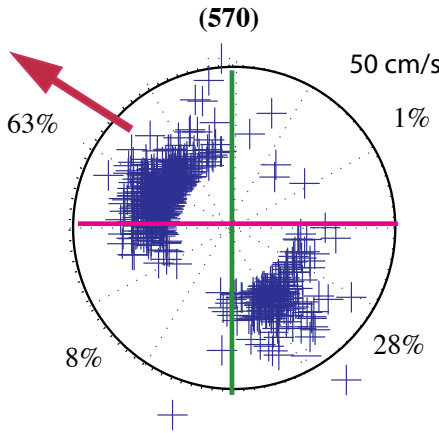

Category 2 events

Figure 16A. Category 1 and 2 internal events (see text) at sites $A 6$ and $A 7$. The numbers in parentheses are the total number of events found in the 2-year baroclinic record. The percentages are the relative number of events found in each directional quadrant. Note the largest currents are usually more than $50 \mathrm{~cm} / \mathrm{s}$ at these sites. Arrow indicates main direction of current.

A3

(257)
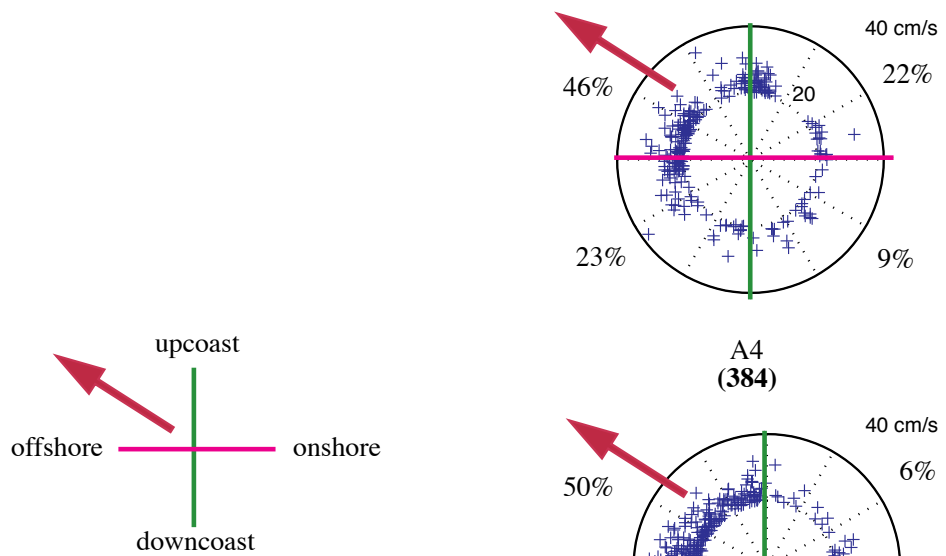

A4

(384)

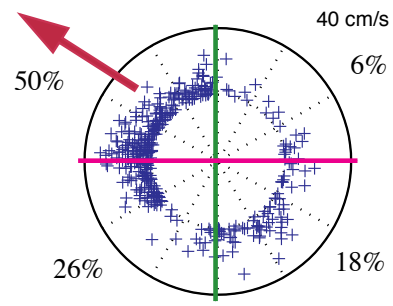

Category 1 events
A3

(63)

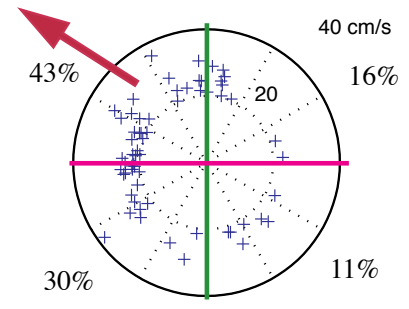

A4

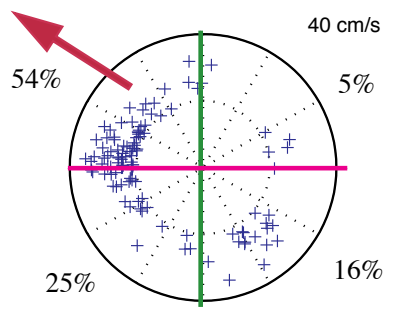

Category 2 events

Figure 16B. Category 1 and 2 internal events (see text) at sites $A 3$ and $A 4$. The numbers in parentheses are the total number of events found in the 2-year baroclinic record. The percentages are the relative number of events found in each directional quadrant. Note the largest currents are more than $40 \mathrm{~cm} / \mathrm{s}$ at these sites. Arrow indicates direction of current. 
as a Kelvin wave, which has an along-shelf length scale of more than a thousand kilometers (Munk and others, 1970; Rosenfeld and Beardsley, 1987; Noble and others, 1987). The theoretical orientation of the tidal-current ellipses is primarily along-shelf, parallel to isobaths. Analytic models suggest that along-shelf variations in semidiurnal sea level and current amplitudes are minimal when a Kelvin wave propagates along a straight coastline (Battisti and Clark, 1982a,b). Hence, one might not expect that the observed amplitudes of the barotropic semidiurnal tides would have noticeable along-shelf spatial gradients in the central SCB.

Changes in the amplitudes of semidiurnal sea-level fluctuations are minimal even if the coastline has a significant along-shelf structure (Rosenfeld and Beardsley, 1987). This is consistent with our observations. The amplitude of the barotropic semidiurnal tidal currents is predicted to change with location when spatial scale for along-shelf variations in topography approach the spatial scale for cross-shelf variations, as it does in the central SCB. The relatively wide shelf in San Pedro Bay abruptly narrows off the Palos Verdes peninsula, then the shelf widens again in Santa Monica Bay. These topographic variations cause some of the along-shelf changes in the measured and modeled tidal-current amplitudes.

Both the measured and modeled barotropic tidalcurrent fields show rapid changes in tidal-current amplitude along the shelf, consistent with the above theory. Some of the differences in these two current files is also caused by short along-shelf topographic length scales. The grid resolution for the modeled tides is $1 \mathrm{~km}$. Hence, in the transition region between the shelves in the two bays and across the narrow Palos Verdes shelf, there may be less than one, or at most, three grid cells used to determine tidal characteristics. The measured increase in tidal-current amplitudes, as in the Kelvin wave from San Pedro Bay and onto the narrow Palos Verdes shelf, may not be well resolved and not predictable by this model.

It is probable that the local dynamics of the semidiurnal tidal-current field vary along the Palos Verdes shelf because the shelf has significant changes in width; southeastern shelfbreak sites are farther from the coast than northwestern sites. The measured tidal currents at the latter sites lie further within the boundary layer caused by the close proximity of the coast. The coastline prevents flow perpendicular to it, causes tidal-current ellipses to narrow, and may affect the local tidal dynamic balances. Note that the smallest tidal currents are found off Point Vicente, where the shelf is narrowest.

It is not just the changes in topography and the relative coastal boundary-layer effects that alter the measured amplitudes of barotropic semidiurnal tidal currents. The measured amplitudes of barotropic tidal currents have significant temporal, as well as spatial, variability. Barotropic tidal-current amplitudes in the long several-year records over the Palos Verdes and San Pedro shelves vary by 20 percent to more than 100 percent in sections of these records that are less than 3 months long. This is not because barotropic tidal currents actually have time-varying amplitudes. Instead, it is probable that semidiurnal internal tidal currents over these shelves have a non-zero depth mean current and a somewhat stable phase over periods of a few months. Slow temporal variations in the

upcoast

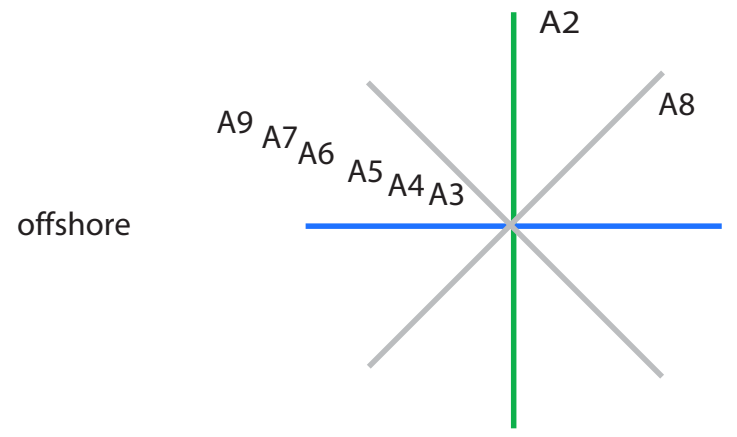

A downcoast

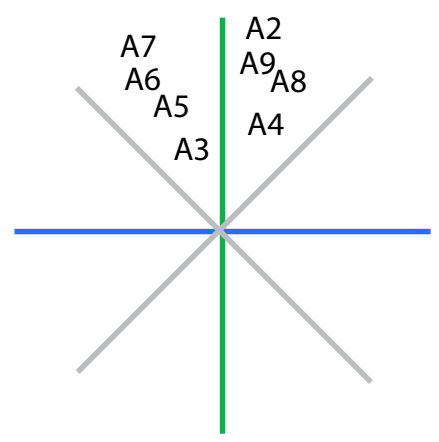

onshore

B

Figure 17. Dominant direction of currents at each site in the primary array with near-bottom speeds greater than $20 \mathrm{~cm} / \mathrm{s}$ - $(A)$ in the baroclinic record and $(B)$ in the raw current record with the baroclinic record removed. 
amplitude and/or orientation of the vertically averaged component of an internal tidal current or the presence of a series of internal tidal bores can interfere with the barotropic tidal currents and augment or diminish their effective amplitude for periods of a few months.

It is clear that long records are needed before one can definitively determine the characteristics of the barotropic semidiurnal tidal currents in this region of the central SCB. It is probable that long records are also needed to determine the characteristics of barotropic tidal currents in most other regions of the central SCB, as internal tidal currents, energetic nonlinear internal tidal currents, and bores with semidiurnal or diurnal frequencies are often found in this area (Noble and others, 2003; Noble and Xu, 2003).

The spatial patterns in the surface semidiurnal tidal, internal tidal, and internal bore currents are similar in that all current fields are strongest southeast of the outfall and generally weaker northwest of it, suggesting that these current fields are dynamically linked. Because the phases of the internal tides are relatively stable over time, it is probable that they were generated by barotropic tidal currents in the SCB, either along the submerged island ridges offshore of the Santa Monica and San Pedro basins or at the shelf break. Generation sites much further offshore would cause the phase of the internal tide to be more random with time (Hendershott, 1981; De Witt and others, 1986). As these internal tides propagate toward the coast, they begin to shoal because the width of the narrow shelf off Palos Verdes is generally much less than the $15-$ to $30-\mathrm{km}$ wavelength of an internal tide. Hence, the internal tides encounter the coastal boundary layer much more quickly than they would on a wider shelf.

It is clearly evident in the asymmetric flow patterns seen in the strong near-bed category 1 and 2 flow events that some portion of the energy in the baroclinic tidal currents transitions into nonlinear internal tides and bores at the shelf break. The strength and offshore flow direction in these near-bed currents matches the characteristics of the internal bores that occur intermittently for several days at tidal frequencies (figs. $14 A$ and $B$ ). The direction of flow in the near-bottom currents suggests that the bores are propagating onshore.

One would expect that dissipation and bottom friction would weaken the nonlinear internal tidal currents and/or bores as they propagate across the shelf. It is known that the energetic internal bores observed at the shelf break in Santa Monica Bay, just northwest of Palos Verdes, lose much of their energy as they propagate onshore over this relatively wide shelf (Noble and Xu, 2003). However, the near-bed currents associated with internal bores off Palos Verdes strengthen as they cross the $35-\mathrm{m}$ isobath along both crossshelf transects (sites A3/A4 and A6/A7). It is probable that dissipation, which normally reduces current amplitudes as an internal bore crosses the shelf, cannot cause the expected weakening of current velocity because the distance between the 65- and 35-m isobaths off Palos Verdes is too short. The concentration of energy as the internal bore propagates into shallow water overcomes dissipative forces.

\section{Transport Patterns for Suspended Sediments}

The common spatial patterns in the distribution of contaminated sediments over the shelf, in the potential for erosion for all sediments in the region, and in the amplitudes of near-bed currents caused by linear and nonlinear semidiurnal tidal currents and bores suggest that these spatial patterns are interconnected. Fine material discharged from the ocean outfall was deposited only at sites upcoast (northwest) and offshore of the outfall. Fine material from the outfall or from any other source did not settle and remain in the region downcoast (southeast) of the outfall.

This spatial pattern in the sediments is consistent with the general direction of flow in the region in that the mean nearbottom currents carried sediments from the outfall upcoast and slightly offshore. However, mean near-bottom currents also flow upcoast southeast of the outfall. They carry suspended material from San Pedro Bay onto the Palos Verdes shelf, material that could potentially be deposited southeast of the outfall, contrary to what was observed. The spatial structure in the mean flow alone cannot account for the complexity in the sediment patterns observed in the region.

Near-bottom surface-wave velocities, which resuspend sediments in water depths found over the Palos Verdes shelf, keep fine materials from depositing and remaining in water depths shallower than $30 \mathrm{~m}$ (Sherwood and others, 2002; Wiberg and others, 2002). However, because they have reasonably uniform amplitude along this shelf, they don't cause the along-shelf structures seen in sediments deposited over the mid and outer shelf.

One needs the along-shelf spatial gradients seen in the near-bed currents associated with surface tides, internal tides, and bores to explain the along-shelf structures in the sediments and in the potential for resuspending sediments over this shelf. Even if a particular near-bed current is not capable of resuspending fine sediments by itself, it does provide a background spatial gradient in energy. That, in combination with more uniform along-shelf flow fields such as those caused by surface waves and subtidal currents, causes the non-uniform distribution of fine sediments seen along the shelf. The more energetic near-bed currents caused by nonlinear internal waves and bores are capable of resuspending and transporting sediments by themselves. The spatial gradients and directions of these currents directly alter the sediment distribution patterns.

Hence, the spatial patterns in the erosive potential for the several semidiurnal and near-semidiurnal current fields match the spatial patterns in the sediment erodability for this region of the shelf. Current amplitudes in these fields are largest southeast of the deposit (sites A6-A9), where sediments are relatively coarse and the potential erodability of the sediments is relatively low. These currents are also stronger in the shallower depths, aiding the currents from surface waves to keep fine sediments from being deposited on the shallower portions of the shelf. Strong near-bed currents associated with internal tides and bores cause fine material to be transported offshore, consistent with observations that fine sediments from 
the outfall are draped over the slope. The near-bottom currents associated with these processes are weakest over the northwestern portion of the Palos Verdes shelf (sites A3-A5), where finer sediments have accumulated.

\section{Conclusions}

Spatial patterns in the fine and contaminated sediments deposited on the Palos Verdes shelf reflect the spatial structures in the local current fields. The deposit of contaminated sediment is primarily found at sites northwest of the local sewage outfall. The local near-bottom surface-wave velocities, which can resuspend these sediments, have a uniform amplitude along isobaths. They do not cause the asymmetric along-shelf pattern seen in the contaminated sediment deposit. The mean currents, while they do not resuspend sediments themselves, do contribute to the asymmetry in the sediment deposit in that they primarily carry resuspended sediments northwestward along the shelf.

However, the mean currents are not the only processes controlling either the spatial patterns in the sediments or the potential for eroding the sediments in this region. The rapidly varying along-shelf structure in the amplitudes of near-bottom currents associated with surface tides, internal tides, and internal bores partially control local sediment distributions in that they cause spatial gradients in the climate for local erosion. These near-bed currents are largest on the southeastern portion of the shelf, where the sediments are coarsest, and weakest toward the northwest, where sediments are finest. They are also stronger inshore, where fine sediments do not accumulate. These near-bed current amplitudes are occasionally strong enough to erode sediments directly. The largest near-bed currents are primarily directed offshore and upcoast; hence they carry fine materials both off and northwestward along the shelf.

Because the spatial patterns in the amplitudes of the surface and internal tidal currents are caused by spatial changes in the topography of the region, these patterns are apt to be permanent features in the regional current fields. The more energetic near-bottom semidiurnal and near-semidiurnal current fields will continue to contribute to the relatively erosive climate southeast of the deposit. The relatively weak current fields will continue to allow finer material to remain over the northwestern portion of the shelf.

The question as to whether some portion of the most highly contaminated sediments, which are buried 10 to 20 $\mathrm{cm}$ below the surface of the sediment deposit, will eventually be uncovered by these spatially varying, potentially erosive currents, cannot be addressed in this study. Even though one could estimate the erosion and transport of material out of the study site by these near-bed currents, it is difficult to estimate the supply of sediment to this shelf from the region downcoast of the study site. The mean near-bed currents in the northwestern portion of San Pedro Bay tend to flow off, rather than along, the shelf. Some of the fine sediment resuspended in this bay may be carried onto the slope and lost to the shelf system. Hence, some of the fine sediment transported off the Palos Verdes shelf by the local flow field may not be replaced; the Palos Verdes shelf could potentially erode. To remain in equilibrium, another sediment source might be needed, such as sediment supplied by the intermittent movement of the Portuguese Bend landslide.

It is clear that changes in sediment supply to the region, either from natural or anthropogenic sources, could change the net balance between sediment deposition and erosion. Further research on and models of the resuspension and transport pathways for sediments downcoast of the Palos Verdes shelf is needed before a definitive answer on the potential for net erosion can be made for this region of the Continental Shelf.

\section{Acknowledgments}

Many agencies and institutions participated in portions of the above studies. The authors would like to thank the County of Los Angeles Sanitation District for providing much of the current and temperature data used in this report and the Environmental Protection Agency for supporting some of the analysis in this report. Anne Gartner and Florence Wong created many of the figures that show the geology and spatial arrays in the region. The ADCIRC model results were from the Spargo and others (2004) report available at http://www. unc.edu/ims/ccats/tides/ENPAC_2003_report.pdf.

\section{References}

Anderson, N.O., 1974, On the calculation of filter coefficients for maximum entropy spectral analysis: Geophysics, v. 39, p. 69-72.

Battisti, D.S., and Clarke, A.J., 1982a, A simple method for estimating barotropic tidal currents on continental margins with specific application to the $\mathrm{M}_{2}$ tide off the Atlantic and Pacific coasts of the United States: Journal of Physical Oceanography, v. 12, p. 8-16.

Battisti, D.S., and Clarke, A.J., 1982b, Estimation of nearshore tidal currents on nonsmooth continental shelves: Journal of Geophysical Research, v. 87, p. 7873-7878.

De Witt, L.M., Levine, M.D., Paulson, C.A., and Burt, W.V., 1986, Semidiurnal internal tide in JASIN: Observations and simulation: Journal of Geophysical Research, v. 91, p. 25812592.

Drake, D. E., Eganhouse, R., and McArthur, W., 2002, Physical and chemical effects of grain aggregates on the Palos Verdes margin, southern California: Continental Shelf Research Special Issue, v. 22, no. 6-7, p. 967-1004.

Eganhouse, R.P. and Pontolillo, J., 2000, Depositional history of organic contaminants on the Palos Verdes Shelf, California: Marine Chemistry, v. 70, p. 317-338.

Foreman, M.G.G., 1977, Manual for tidal heights analysis and prediction: Pacific Marine Science, Institute of Ocean 
Sciences, Patricia Bay, Sydney, B.C., Report 77-10, 97 p.

Foreman, M.G.G., 1978, Manual for tidal currents analysis and prediction: Pacific Marine Science, Institute of Ocean Sciences, Patricia Bay, Sydney, B.C., Report 78-6, 70 p.

Hendershott, M.C., 1981, Long waves and ocean tides, in Evolution of physical oceanography, Warren, B.A. and Wunsch, C., (eds.): MIT Press, p. 292-341.

Los Angeles County Sanitation District, 1992, Palos Verdes ocean monitoring-Sediment Report 1992: Annual Report, Sanitation Districts of Los Angeles County, Whittier, Calif.

Los Angeles County Sanitation District, 1998, Palos Verdes ocean monitoring: Annual Report, 1998: Sanitation Districts of Los Angeles County, Whittier, Calif.

Lee, H.J., Sherwood, C.R., Drake, D.E., Edwards, B.D., Wong, F., and Hamer, M., 2002, Spatial and temporal distribution of contaminated, effluent-affected sediment on the Palos Verdes margin, southern California, in Sedimentation processes, DDT, and the Palos Verdes margin: Continental Shelf Research Special Issue, v. 22, no. 6-7, p. 859-880.

Lee, H.J., and Wiberg, P.L. (eds.), 2002, Sedimentation processes, DDT, and the Palos Verdes margin: Continental Shelf Research Special Issue, v. 22, no. 6-7, p. 835-1115.

Munk, W., Snodgrass, F., and Wimbush, M., 1970, Tides off-shore - transition from California coastal to deep-sea waters: Geophysical Fluid Dynamics, v. 1, p. 161-235.

Murray, C.J. and Chien, Y., 2006, Geostatistical analysis of sediment erodibility on the Palos Verdes shelf, offshore Southern California: Letter report, Pacific Northwest National Laboratory, September 2006.

Noble, M.A., Rosenfeld, L., Gardner, J., Beardsley, R.C., and Smith, R., 1987, Tidal currents seaward of the northern California continental shelf: Journal of Geophysical Research, v. 92, no. C2, p. 1733-1744.

Noble, M.A., Ryan, H.F., and Wiberg, P.L., 2002, The dynamics of subtidal poleward flows over a narrow continental shelf, Palos Verdes, CA, in Sedimentation processes, DDT, and the Palos Verdes margin: Continental Shelf Research Special Issue, v. 22, no. 6-7, p. 923-944.

Noble, M.A., and Xu, J.P., 2003, Observations of largeamplitude cross-shore internal bores near the shelf break, Santa Monica, CA: Marine Environmental Research, v. 56, no. 1-2, p. 127-149.

Noble, M.A., Xu, J.P., Rosenfeld, L., Largier, J., Hamilton, P., Jones, B., and Robertson, G., 2003, Huntington Beach shoreline contamination investigation, phase III, Executive Summary - Coastal circulation and transport patterns; the likelihood of OCSD's plume impacting Huntington Beach shoreline: U.S. Geological Survey Open-File Report 03-62 [http://pubs.usgs.gov/of/2003/of03-62/].

Pawlowicz, R., Beardsley, B., and Lentz, S., 2002, Classical tidal harmonic analysis including error estimates in MATLAB using T_TIDE: Computers and Geosciences, v. 28, p. 929-937.

Rhoads, D.C., and Germano, J.D., 1986, Interpreting longterm changes in benthic community structure - a new protocol: Hydrobiologia, v. 142, p. 291-308.

Rosenfeld, L.K., and Beardsley, R.C., 1987. Barotropic semidiurnal tidal currents off Northern California during the Coastal Ocean Dynamics Experiment (CODE): Journal of Geophysical Research, v. 92, no. C2, p. 1721-1732.

Science Applications International Corporation, 2004, Analysis of moored oceanographic data acquired on the Palos Verdes shelf by the LACSD during the period from November 2000 to August 2003: Science Applications International Corporation, SAIC Report 659, Newport, Rhode Island.

Science Applications International Corporation, 2005a, Data report for the summer 2004 Geotechnical Measurement Program conducted on the Palos Verdes Shelf: Science Applications International Corporation, SAIC Report 676, Newport, Rhode Island.

Science Applications International Corporation, 2005b, Data report for the 2004 oceanographic measurement program conducted on the Palos Verdes shelf: Science Applications International Corporation, SAIC Report 694, Newport, Rhode Island.

Southern California Coastal Water Research Project, 1999, Annual report 1997-98: Southern California Coastal Water Research Project Authority, Westminster, Calif., 210 p.

Sherwood, C.R., Drake, D.E., Wiberg, P.L., and Wheatcroft, R.A., 2002, Prediction of the fate of $\mathrm{p}, \mathrm{p}^{1}$-DDE in sediment on the Palos Verdes shelf, California, USA, in Sedimentation processes, DDT, and the Palos Verdes margin: Continental Shelf Research Special Issue, v. 22, no. 6-7, p. 1025-1058.

Spargo, E.A., Westerink, J.J., Luettich, R.A., Jr., and Mark, D.J., 2004, ENPAC 2003-A tidal constituent database for eastern north Pacific Ocean: U.S. Army Corps of Engineers Engineer Research and Development Center, Coastal and Hydraulics Laboratory, ERDC/CHL T-04-12.

Wiberg, P.L, Drake, D.E., Harris, C.K., and Noble, M., 2002, Sediment transport on the Palos Verdes shelf over seasonal to decadal time scales, in Sedimentation processes, DDT, and the Palos Verdes margin: Continental Shelf Research Special Issue, v. 22, no. 6-7, p. 987-1004. 
This page intentionally left blank 

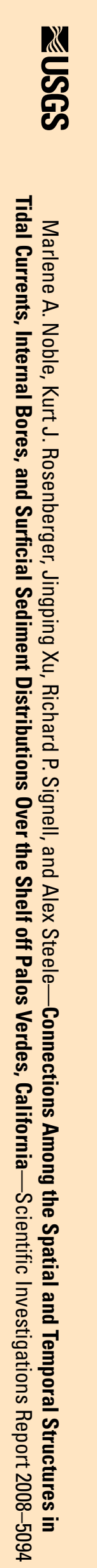